ARCHIVO ESPAÑOL DE ARTE, LXXXV, 340

OCTUBRE-DICIEMBRE 2012, pp. 303-328

ISSN: 0004-0428

\title{
LA SUBIDA AL CALVARIO DE SCIPIONE PULZONE PARA MARCANTONIO COLONNA
}

\author{
ANTONIO VANNUGLi \\ Universidad para Extranjeros de Perugia
}

\begin{abstract}
Este artículo presenta la Subida al Calvario que Pulzone pintó en 1581-83 para Marcantonio Colonna, entonces virrey de Sicilia. Al poco de recibirlo, el comitente se lo regaló a Mateo Vázquez, secretario de Felipe II, en testimonio de amistad y para agradecerle el apoyo a la carrera eclesiástica de su hijo Ascanio. A la muerte de Vázquez lo heredó su sobrino homónimo, arcediano de Carmona; éste lo llevó a Sevilla donde a comienzos del siglo XVII lo describió Pacheco. Amén de examinar la iconografía en conexión con los modelos de Sebastiano del Piombo y Rafael y las otras representaciones del tema en la pintura romana coetánea, se señala que también el cardenal Ferdinando de' Medici pensó enviar a España la réplica que el mismo autor le había hecho: esto confirma que la obra de Pulzone pareció poder satisfacer perfectamente la predilección española, muy bien conocida en Roma, por el patetismo en el arte religioso.

Palabras clave: Scipione Pulzone; Marcantonio Colonna; Ascanio Colonna; Mateo Vázquez de Leca; Francisco Pacheco; Caravaggio; Ferdinando de' Medici; Jacopo Zucchi.
\end{abstract}

\section{SCIPIONE PULZONE'S WAY TO CALVARY FOR MARCANTONIO COLONNA}

This article presents the Way to Calvary painted by Pulzone in 1581-83 for Marcantonio Colonna, then viceroy of Sicily. The latter sent it as a gift to Mateo Vázquez, secretary to Philip II, in testimony of their friendship and to thank him for supporting the ecclesiastical career of his son Ascanio, who delivered the painting in Madrid. When Vázquez died, it was inherited by his homonymous nephew, archdeacon of Carmona, who took it to Seville where Pacheco described it in the early $17^{\text {th }}$ century. The author examines the painting's iconography in connexion with Raphael's and Sebastiano del Piombo's models, as well as other representations in Roman painting of the period. He also points out that cardinal Ferdinando de' Medici intended to send to Spain the autograph replica made for him; this confirms that Pulzone's picture seems to have perfectly met the Spanish predilection, well-known in Rome, for the pathetic in religious art.

Key words: Scipione Pulzone; Marcantonio Colonna; Ascanio Colonna; Mateo Vázquez de Leca; Francisco Pacheco; Caravaggio; Ferdinando de' Medici; Jacopo Zucchi.

Casi cuatro siglos después de haberse extraviado ha vuelto a aparecer en el mercado de arte italiano la célebre pintura de Scipione Pulzone que representa la Subida al Calvario con Cristo llevando la cruz a cuestas, acompañado por tres sayones y seguido por la Virgen, la Magdalena, 
san Juan Evangelista y más atrás un soldado, figuras todas de medio cuerpo ${ }^{1}$. El cuadro, que el artista pintó entre 1581 y 1583 por encargo de Marcantonio Colonna, fue adquirido en Varese por el actual propietario y constituye sin duda la más importante contribución que se haya podido aportar a su catálogo en los últimos años².

La más antigua mención de la Subida al Calvario se lee, en vida del autor y al poco de completarse su ejecución, en el Riposo de Raffaello Borghini, donde con el fin de alabar a Scipione no sólo como retratista sino también como pintor de historia se recuerdan "due bellissime tavole [i.e. pinturas, sin implicar de ninguna manera el soporte] a olio": la primera es el gran lienzo de la Inmaculada Concepción con los santos Andrés, Clara, Francisco, Catalina de Alejandría y el pequeño Andrea Cesi originalmente sobre el altar de la segunda capilla lateral a mano derecha $-\mathrm{y}$ no sobre el altar mayor- de la antigua iglesia de los Capuchinos de Roma, pero que ya en el siglo XVII fue trasladado a San Francisco en Ronciglione, fechado en 1581 y realizado para Porzia dell'Anguillara", y a continuación el "Christo, che porta la Croce con le turbe, e dietro la Madonna con le Marie, che piagne; e questa è andata in Cicilia al Sig. Marcantonio Colonna; e sono state queste due opere molto lodate"4. Los tiempos y las circunstancias de la ejecución del cuadro han sido aclaradas gracias a la reciente publicación de la copia, guardada en el archivo Colonna de Subiaco, de una carta que Ottaviano Villa, agente de los Colonna en Roma, escribió el 19 de mayo de 1581 a Marcantonio II Colonna, entonces virrey de Sicilia: "Io non ho mancato di sollecitare Scipione pittore per conto di [?]fornire il quadro di N[ostro] S[ignore] con la croce in collo; e sebben promette di voler fare assai, ci attende molto poco; sarà bene che V[ostra] E[ccellenza] ce ne scriva due parole" . Todavía más recientemente, basándose en los pagos registrados en los libros de cuentas de los Colonna se ha podido precisar que el 30 de enero de 1579 Pulzone cobró la segunda mitad de un adelanto de 100 escudos y que recibió el saldo de 200 escudos más, por la cuantiosa suma de 300 escudos en total, el 16 de mayo de $1583^{6}$.

Marcantonio Colonna, III duque de Paliano, nació en 1535 y como es sabido estuvo al mando de la flota pontificia en la batalla de Lepanto. Fue gran condestable del reino de Nápoles y súbdito fiel de Felipe II, quien impuso al papa Pío IV que le devolviese el feudo que le había sido confiscado por el predecesor Paulo IV. El 4 de enero de 1577 el rey, tras haberlo llamado a la corte en el otoño anterior, lo nombró virrey de Sicilia, donde el duque llegó en la primavera siguiente para quedarse, siéndole renovado el encargo por un segundo trienio, hasta el primero de mayo de 1584, día en que se embarcó para Roma; allí no se detuvo más de una semana, antes

1 Óleo sobre lienzo, 120,5 × 165,5 cm. El lienzo fue forrado en el siglo XX. Debido a las características de la ensambladura, el bastidor parece mucho más antiguo y podría ser el original. Agradezco la ayuda y los consejos recibidos a Ugo Bazzotti, Agustín Bustamante, Francesca Klein, Antonio González Polvillo, José Martínez Millán, Almudena Pérez de Tudela, José María Ruiz Manero, Claudio Strinati y Miguel Ángel Zalama.

2 Sobre Scipione Pulzone (GAETA, hacia 1545-Roma, 1 de febrero de 1598) véase DeRn, 2003, y además Redín Michaus, 2002: 77-86. Pérez de Tudela, 2004: 34-45. En 2013 la Soprintendenza de Lazio dedicará al pintor una exposición en GAETA.

3 Baglione, 1642: 53 (véase también Röttgen en Baglione, 1995: Vol. II, 426). Dern, 2003: 46-48 y 124-126 núm. 30. Pupillo, 2005: 294 núm. 112. Ricci, 2010: 70-73. La inscripción con la fecha de 1581, ya no legible en su totalidad desde hace mucho tiempo -hoy en día sólo se detectan las letras "MDL[...]"- es referida por MorONI, 1852: 104, quien vio el lienzo ya en su actual ubicación: "il quadro dell'Assunta, dipinto da Scipione Gaetano nel 1581". De aquí debe proceder la información dada en VENTURI, 1934: 762, sin indicación de paradero.

${ }^{4}$ Borghini, 1584: 578 .

${ }^{5}$ La carta fue publicada por DERN, 2003: 44, nota 116, 198, núm. 101 y 205, doc. 11

${ }^{6}$ Nicolai, 2006: 302-303 y 310, doc. 6: "1579, 30 gen., pagherete a ms. Scipione Gaetano pittore sc. 50 di moneta che con altri cinquanta son cento e sono a buon conto di un quadro che fa per nostro servitio", y "1583, 16 maggio, Zanchini e Doni, vi piacerà pagare a Scipione pittore scudi duegento di moneta sono a complimento di scudi 300 simili per il prezzo di un quadro del Salvatore con la Croce in collo che lui ha fatto". 


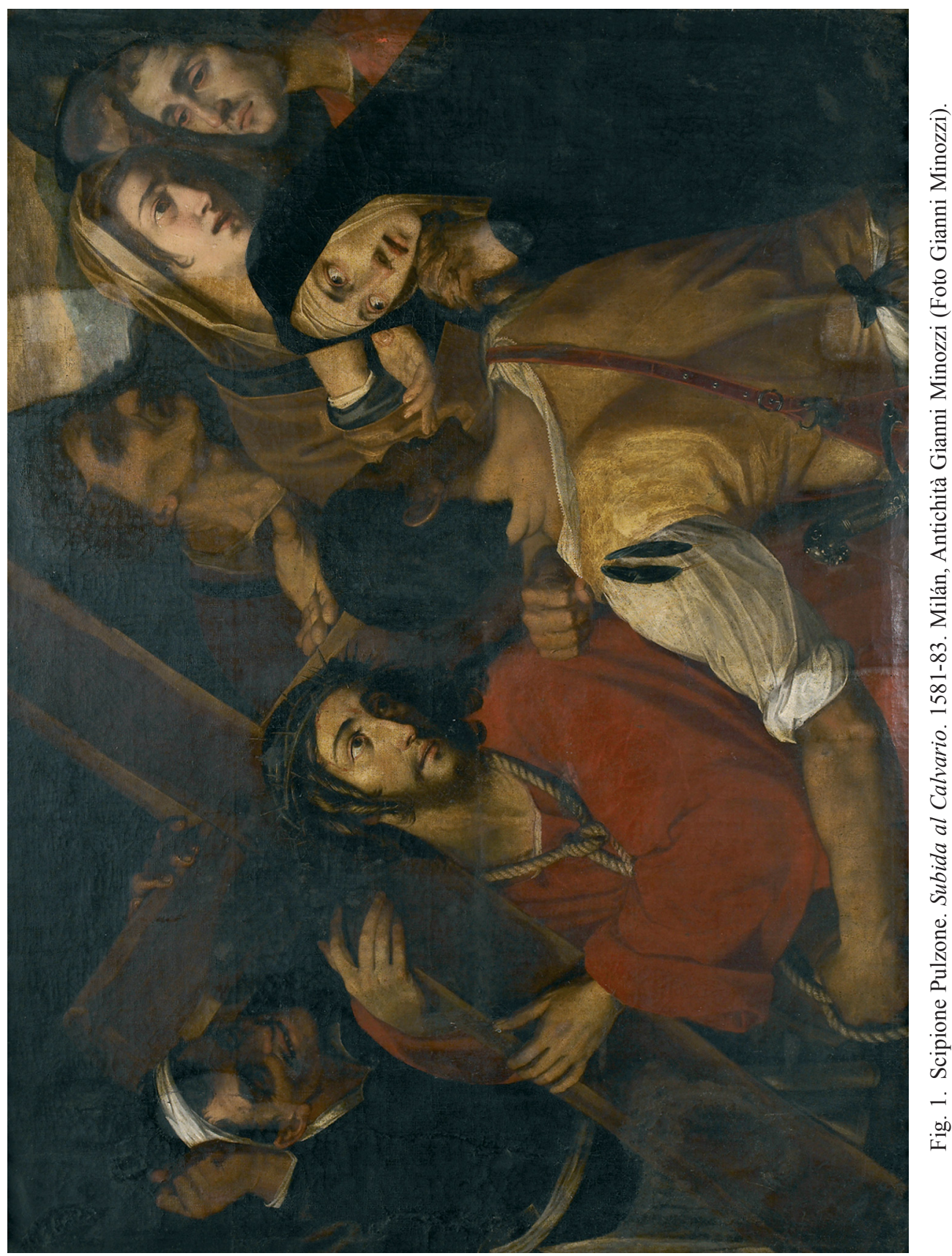

Arch. esp. arte, LXXXv, 340, octUBRE-DICIEMBRE 2012, 303-328, ISSN: 0004-0428 


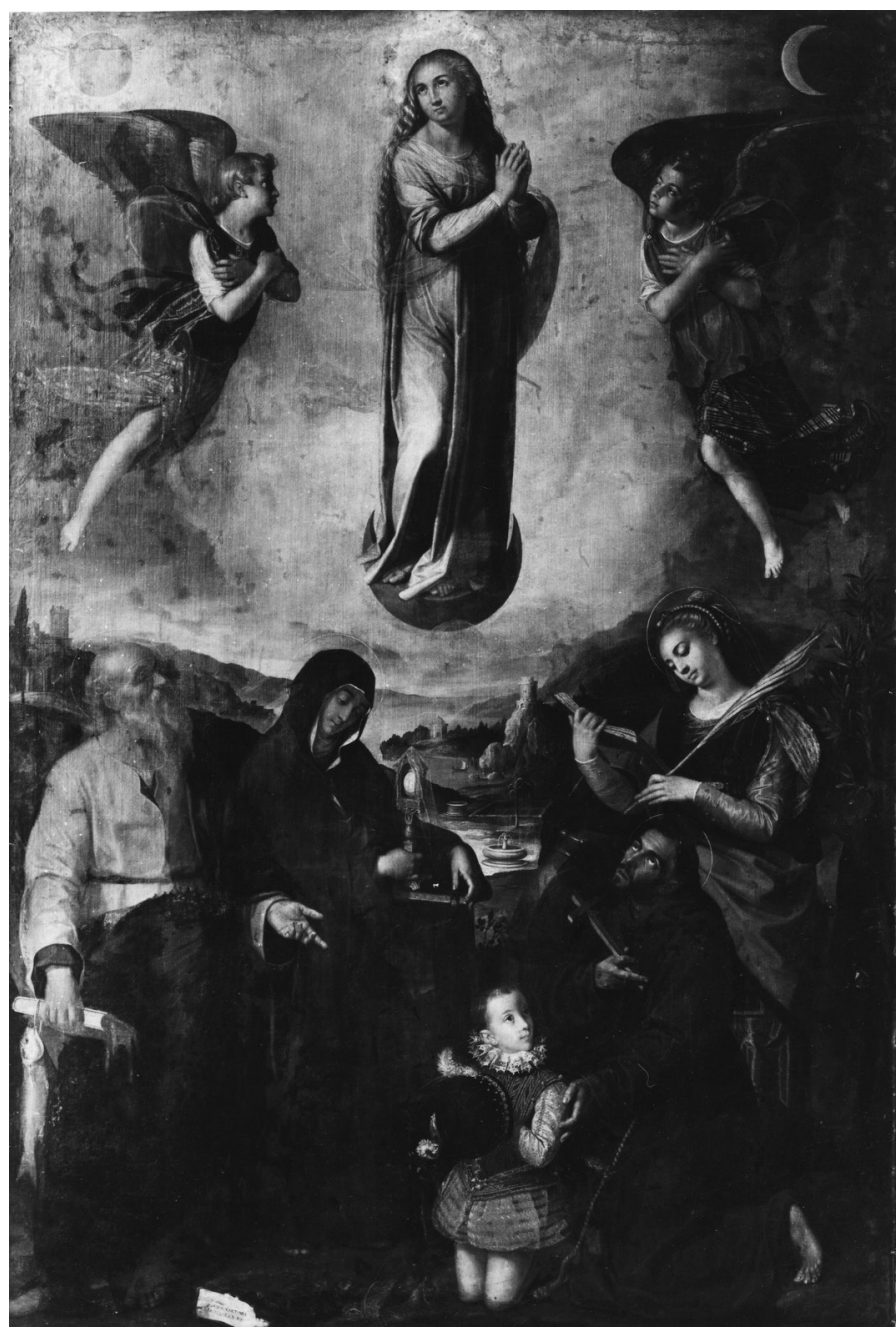

Fig. 2. Scipione Pulzone. Inmaculada Concepción con los santos Andrés, Clara, Francisco de Asís, Catalina de Alejandría y el pequeño Andrea Cesi. 1581. Ronciglione, San Francesco (Foto Gabinetto Fotografico Nazionale, Roma).

de emprender el fatal viaje hacia Madrid7 . En la villa de Bracciano Colonna, estando huésped en el castillo del cuñado Paolo Giordano Orsini, convocó el 22 de junio a Pulzone para que lo retratara a la vista del gran retrato de pie, de cuerpo entero, hoy en día expuesto en la Galería Colonna de Roma, repetido varias veces en diferentes formatos ${ }^{8}$. En aquella época Scipione ya llevaba dieciséis años relacionado con el duque, al haber recibido el 4 de febrero de 1568 el primer pago de él por un retrato de Felipe II, presumiblemente sacado de Tiziano, y haber

7 Sobre Marcantonio Colonna (Civita Lavinia, hoy Lanuvio, 26 de febrero de 1535-Medinaceli, 1 de agosto de 1584): Rivero RodríGuez, 1994: 305-378. BAZZANo, 2003. BAZZANo, 2007: 281-293.

8 DERN, 2003: 50-52 y 131-133, núm. 35. NiCOLAI, 2006: 304 y 318-319, docs. 26-30. 
realizado entre 1574 y 1575 para el desaparecido altar de los Colonna situado bajo el tabernáculo de las reliquias en San Juan de Letrán su primera doble obra pública en Roma, una Santa María Magdalena penitente y una efigie póstuma del papa Martín V Colonna en oración, pinturas ambas colgadas actualmente en el cercano coro de los canónigos ${ }^{9}$. En medio de estas comisiones, pues, se inserta la de la Subida al Calvario, y no puede olvidarse la acción promocional que seguramente el virrey realizó en Sicilia a favor del artista y que a partir de 1584 le procuraría más de un encargo público procedente de la isla, en particular de la orden capuchina.

La sucesiva, fundamental y por desgracia última huella de la Subida al Calvario, que al ser pintura particular no se encuentra citada en la biografía de Pulzone compuesta por Giovanni Baglione ${ }^{10}$, se remonta a 1638 y gracias a la detallada descripción se revela determinante para confirmar, a pesar de la lejanía geográfica, la identidad del cuadro que aquí se da a conocer. En el manuscrito del Arte de la pintura Francisco Pacheco elige detenerse, como ejemplo ideal del "acabado" en las pinturas, justamente sobre la obra en cuestión: "Pero traeré a la memoria una sola que el año referido [1607], traxo de la Corte a esta ciudad [Sevilla] D. Mateo Vásquez, Arcediano de Carmona [...], es un cuadro que pintó en Roma Cipión Gaetano el año de 1581; presentado del Cardenal Ascanio Colona a su tío Mateo Vásquez (Secretario que fue de

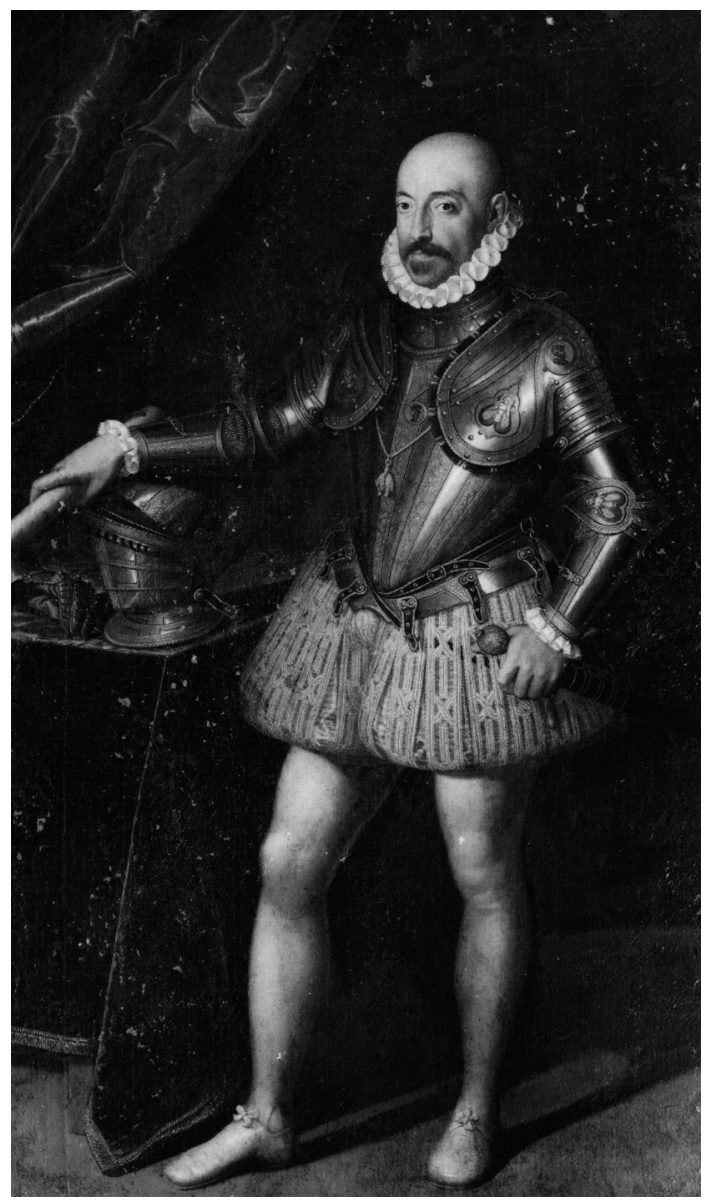

Fig. 3. Scipione Pulzone. Marcantonio Colonna. 1584. Roma, Galería Colonna (Foto Arte Fotográfica, Roma). Filipo II) de cinco cuartas de alto y siete de ancho, de figuras de medio cuerpo; un Cristo con la cruz a cuestas cercado de crueles ministros, y la Virgen Nuestra Señora, San Juan y la Madalena, que afligidos le siguen. Está mirando con grave y varonil compasión el Redentor a la Sagrada Virgen, y ella a él, con tanto afecto y ternura que moverán a piedad las piedras. Donde, maravillosamente, executó el pintor la semejanza del rostro del Hijo y de la Madre, particularmente en los ojos, que, a mi ver, no se ha pintado cosa más viva, o no he visto (por decirlo mejor) de ningún artífice, ojos que así me admiren. Vese el acabado de la barba del Salvador con tanta paciencia que en su sutileza de pelo sobra a las pinturas de Alberto Durero (por decir más que de Morales). Pues las manos del Señor, con que

9 Dern, 2003: 29-31 y 107-110 núms. 18-19. NicolaI, 2006: 296-302, que documenta los pagos: 105 escudos romanos por la Magdalena y 80 por el Martín V. Los dos lienzos se citan en BAgLione, 1643: 53 (véase también la nota de Hess a BAGLIONE, 1995: Vol. II, 425-526), pero el mismo autor describe más detalladamente su antigua ubicación en Baglione (1639), 1990: 133. Barroero, 1990: 147.

10 Baglione, 1642: 52-54. 


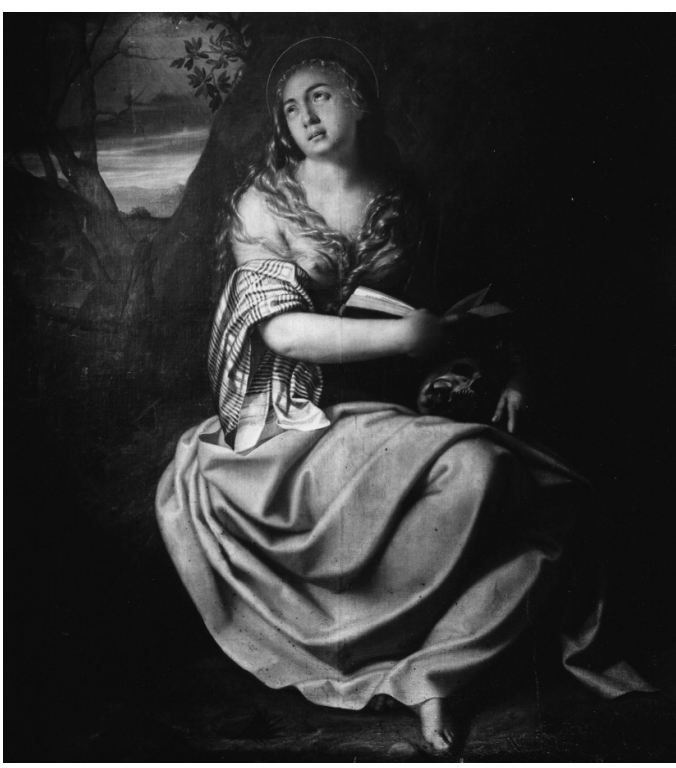

Fig. 4. Scipione Pulzone. Santa María Magdalena penitente. 1574-75. Roma, San Juan de Letrán (Foto Gabinetto Fotografico Nazionale, Roma).

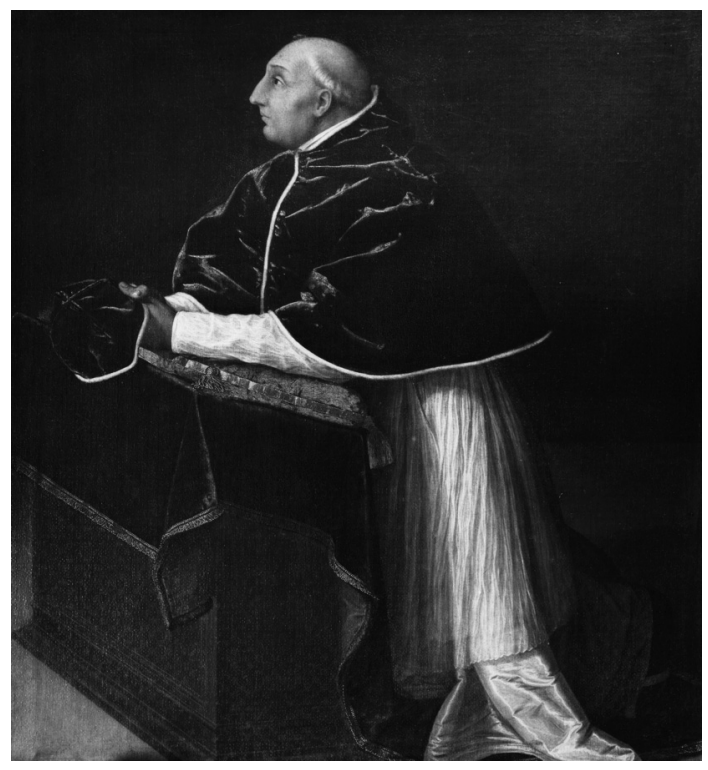

Fig. 5. Scipione Pulzone, Martín V Colonna en oración. 1574-75. Roma. San Juan de Letrán (Foto Fratelli Alinari, Roma).

abraza la cruz, son de hombre vivo; parecen en ellas las varias tintas que hace la carne natural, y la distinción del color de ella y de las uñas con tanto primor que no puede ser más. Es pintura de dientes y uñas porque se defiende con la dificultad de su acabado, que es tal, que el madero de la cruz, teniendo la mano sobre él y tocando el lienzo, todavía está un hombre dudoso si es natural o pintado. Cuando vi esta pintura dixe, osadamente, como aquí, mi sentimiento"11.

Por lo tanto, la Subida al Calvario habría sido regalada a Mateo Vázquez de Leca, poderoso secretario personal de Felipe II a partir de $1573^{12}$, por parte del cardenal Ascanio Colonna, para pasar como consecuencia de la muerte de aquél en 1591 a su sobrino homónimo, arcediano de Carmona, quien en 1607 lo llevaría consigo a Sevilla. Allí Pacheco tuvo la oportunidad de admirarlo mostrándose bien informado sobre el año de ejecución, tal vez por haberlo leído en el reverso del lienzo original, que el forro esconde actualmente a la vista, tal vez por haberlo escuchado del mismo propietario. No hay que olvidar que al artista sevillano, próximo y posiblemente afiliado a la misma Congregación de Granada de la que Mateo Vázquez sobrino era uno de los miembros más destacados, se debe el más conocido retrato del arcediano, aunque sacado necesariamente de una efigie de época anterior por aparecer demasiado joven para sus 47 años y sobre todo por haber sido realizada la pintura, que está firmada y fechada en 1621 y en la actualidad se encuentra en la colección del marqués de la Reunión, cuando éste se encontraba en Roma. Pacheco lo representa en adoración de la Inmaculada Concepción, como eterno recuerdo del papel de primer plano que Mateo Vázquez desempeñó en la promoción y difusión de esta doctrina y que a finales de 1616 lo llevó a la corte pontificia de Paulo V, donde el clérigo

11 Pacheco, 1990: 418-419. Sobre el pasaje llamó la atención Ruiz Manero, 1995: 376-378. Véase también Dern, 2003: 44-45.

12 Sobre Mateo Vázquez de Leca (h. 1543-Madrid, 5 de mayo de 1591): Escudero, 1969: Vol. I, 187-193. LovetT, 1977. Carlos Morales y Martínez Millán, 1998: 500-502. GonZalo SÁnchez-Molero, 2005: 813-846. 


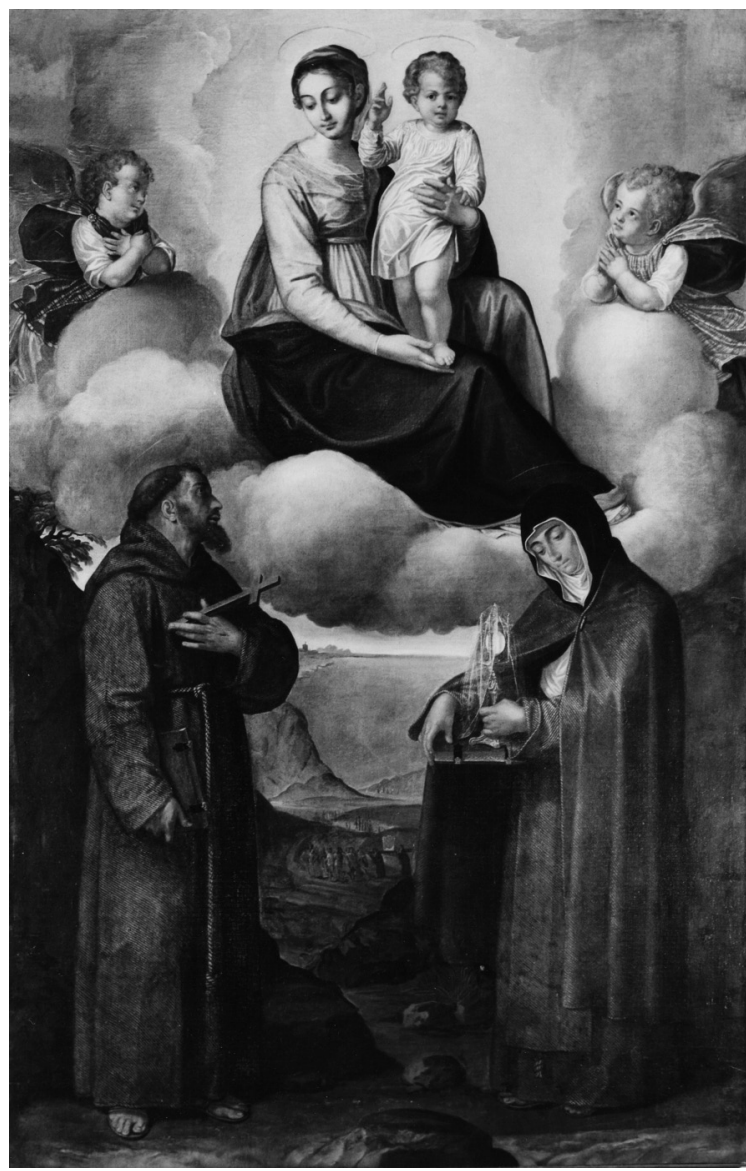

Fig. 6. Scipione Pulzone, Virgen con el Niño Jesús y los santos Francisco y Clara. 1584. Milazzo, Capuchinos (Foto Publifoto, Palermo).

andaluz permaneció durante ocho años ${ }^{13}$. Por su lado, el inestimable testimonio contenido en el Arte de la pintura induce a interrogarse sobre los tiempos, las modalidades y las razones del regalo ofrecido a su tío el secretario real ${ }^{14}$.

Nacido en 1560 y único hijo varón de Marcantonio que llegó a la edad adulta, Ascanio fue destinado a la carrera eclesiástica y en septiembre de 1576 viajó con su padre a España, donde

13 Sobre Mateo Vázquez de Leca sobrino del secretario real (Sevilla, 11 de noviembre de 1573-11 de junio de 1649), que adoptó los apellidos maternos al ser hijo de María, hermana del secretario, y de su primer esposo, el italiano Andrea Barrasi con quien estuvo casada de 1569 a 1578, véase HAZAÑas y LA RÚA, 1918. GonZÁlez PolviLlo, 2009/10: 67-72. Sobre la misión de 1616 en defensa de la Inmaculada: StRATTON, 1994: 67-87. CACHO, 2003: 415-426. Moretti, 2005: 79-89. Gutiérrez Pastor 2007: 268-276. AnSELmi, 2008: 242-246. Martínez Millán, 2008: 220-226.

${ }^{14} \mathrm{Al}$ tema de los regalos diplomáticos se dedicó el simposio L'arte del dono. Scambio culturale tra Italia e Spagna 1550-1650, que tuvo lugar el 14 y 15 de enero de 2008 en la Biblioteca Hertziana de Roma y cuyas actas, a cargo de Von Bernstorff, Ebert-Schifferer y Kubersky-Piredda, están en prensa por la editorial Silvana de Milán. Para los Medici véase también Mulcahy, 1998: 166-180. Salort y Kubersky-Piredda, 2006: 660-665. Salort y KuberSKyPIREDDA, 2007: 224-231. 
se quedó para estudiar en Alcalá de Henares y luego en Salamanca, hasta licenciarse in utroque iure. Estrechamente relacionado con el rey al igual que su padre, en calidad de miembro de la Academia Complutense tuvo la ocasión de leer en 1581 y 1585 dos oraciones dedicadas a él y fue a instancias del propio Felipe II que el 16 de noviembre de 1586 el papa Sixto V le otorgó el capelo cardenalicio. En aquellas mismas semanas, ya fallecido Marcantonio desde hacía dos años, Ascanio concluyó su primera larga estancia en España y con motivo del inminente consistorio emprendió el viaje para Roma, donde desarrolló una intensa actividad en la curia pontificia. Sin embargo a la vuelta del siglo, deseoso de obtener nuevos encargos y satisfacciones, decidió regresar a la tierra que consideraba su segunda patria y que, como solía decir, lo había criado como a un hijo: el pretexto se lo ofreció la muerte prematura, ocurrida el 17 de agosto de 1600, de su cuñado Luis Enríquez de Cabrera, VIII almirante de Castilla y IV conde de Medina de Rioseco, quien había casado en 1587 con su hermana Vittoria. Después de juntarse con ella en Valladolid el 28 de noviembre, dos meses antes del traslado de la corte, en 1601 Ascanio fue nombrado por Felipe III virrey de Aragón y residió en Zaragoza desde 1602 hasta mayo de 1605, cuando volvió para siempre a Roma donde murió tres años más tarde ${ }^{15}$.

Puesto que en 1600, cuando tuvo inicio la segunda estadía de Ascanio Colonna en España, el secretario Mateo Vázquez de Leca estaba muerto desde hacía ya nueve años, es obligatorio

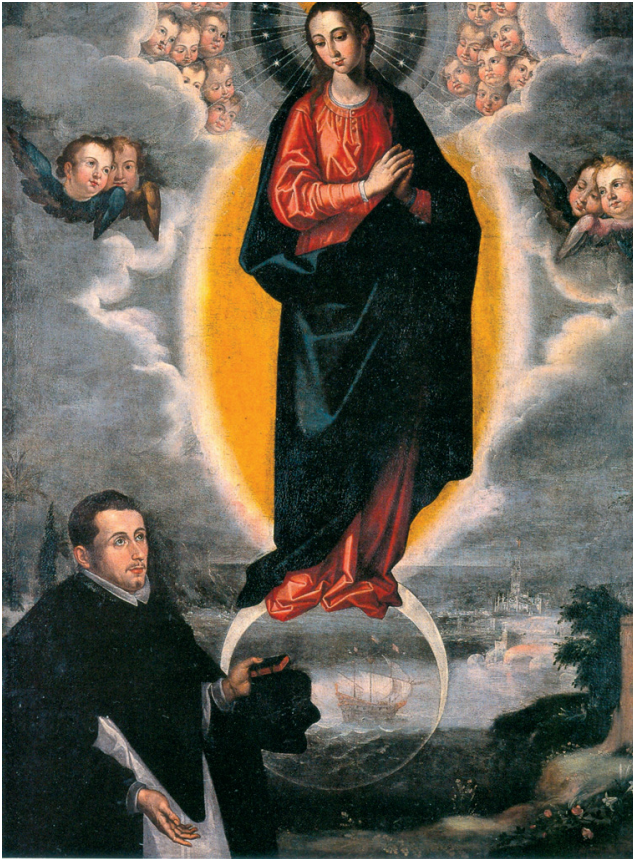

Fig. 7. Francisco Pacheco. Inmaculada Concepción con Mateo Vázquez de Leca. 1621. Sevilla, colección del marqués de la Reunión (Foto Antonio González Polvillo). deducir que la donación del lienzo de la Subida al Calvario tuvo lugar antes de que el primero alcanzara la púrpura. Si bien la biografía de Ascanio Colonna ya ofrece motivos de sobra que podrían justificar un regalo de ese tipo, lo que nos permite determinar cómo fueron realmente las cosas es una carta que el propio duque, padre del futuro cardenal, escribió al secretario real, su protector y referente favorito en la corte y con el que mantuvo correspondencia durante muchos años ${ }^{16}$. La carta, fechada el 29 de abril de 1583, llegó con el archivo personal de Vázquez al Instituto de Valencia de Don Juan y merece ser transcrita integralmente: "Muy Illtre. Sr./ Por haverme contentado un quadro del Salvador con la cruz al hombro que es mano de un pintor famoso y amigo mio, y sabiendo quan inclinado es Vuestra Señoria a cosas de tanta devocion como lo es esta, me ha parecido embiarsele. Pidole por merced que lo accepte y juntamente el buen animo y voluntad de quien se lo da, y si Vuestra Señoria tendra inclinacion a alguna otra cosa de pintura me lo avise que luego se hara, y sin que me cueste un solo real, porque como digo el Pintor no me lo lleva por ser mi amigo. Y Nuestro Señor la muy Illtre. persona de Vuestra Señoria guarde y accreciente

\footnotetext{
${ }^{15}$ Sobre Ascanio Colonna (Marino, 27 de abril de 1560-Roma, 17 de mayo de 1608): PetruCCI, 1982: 275-278. Como se sabe en 1585 Cervantes le dedicó su novela La Galatea. A las relaciones entre los Colonna y España en el siglo XVII se dedica DANDELET, 2007: 543-549.

16 BAZZANO, 2003: 503.
} 


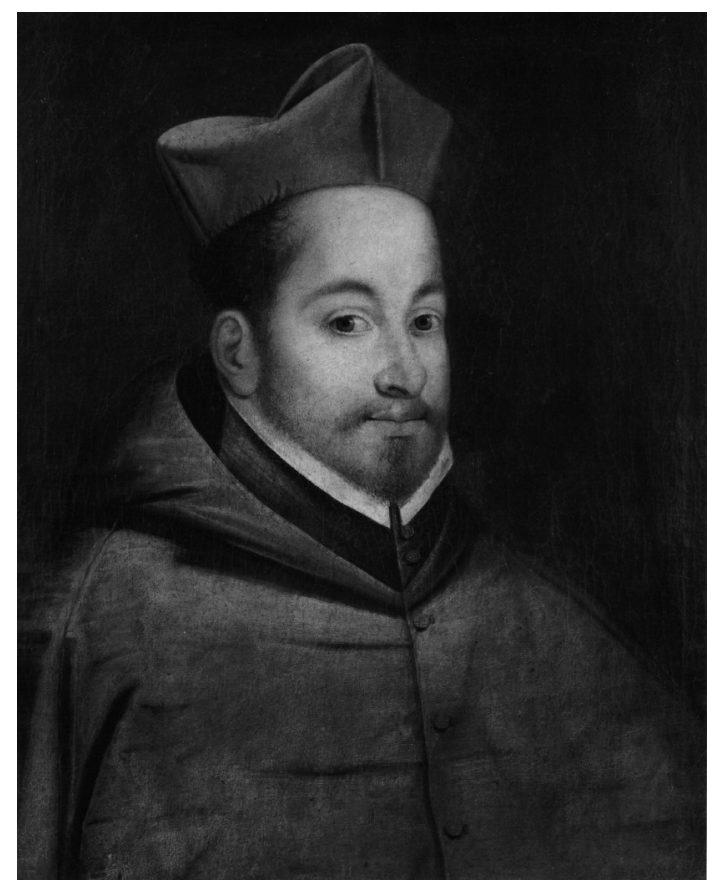

Fig. 8. Anónimo romano de finales del siglo XVI. Ascanio Colonna. Hacia 1587. Roma, Galería Colonna (Foto Arte Fotográfica, Roma).

Fig. 9. Scipione Pulzone. Crucifixión. 1583-86. Roma, Santa María in Vallicella (Foto Gabinetto Fotografico Nazionale, Roma).

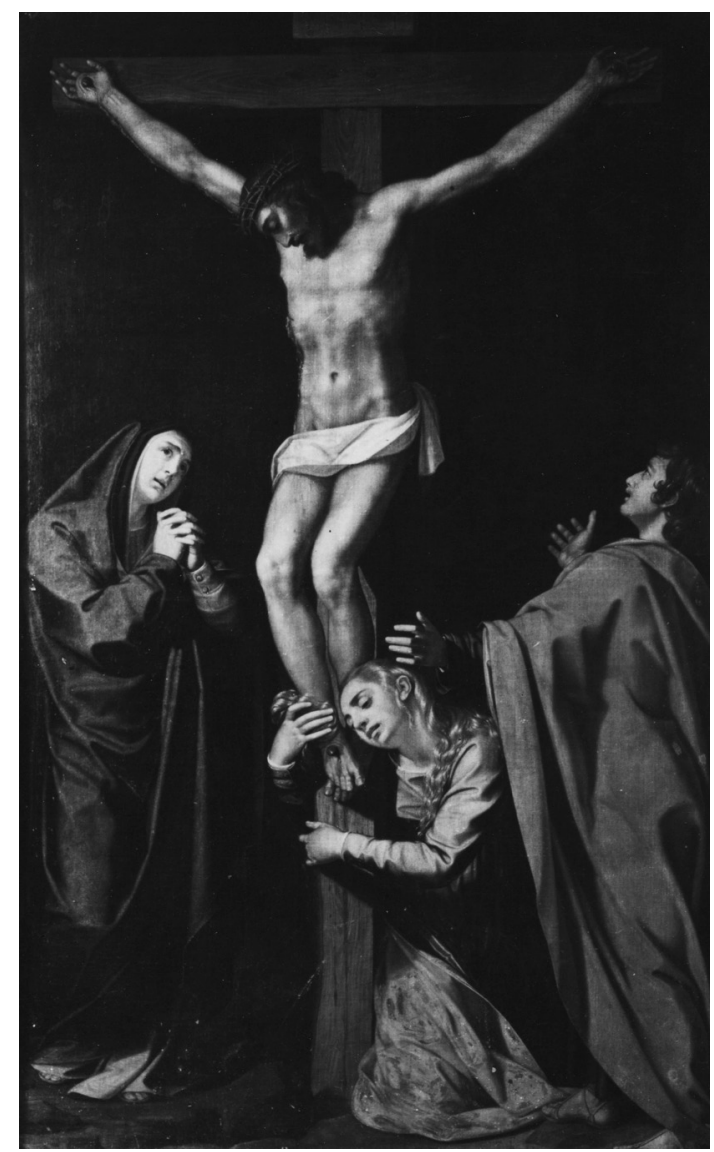

como desea. De Palermo 29 de abril 1583/ Servidor de Vuestra Señoria muy Illtre. Marco Antonio Colonna"17.

Aparte de cualquier consideración sobre la insistencia, seguramente obsequiosa, de Marcantonio Colonna respecto a su amistad con el innominado Pulzone ${ }^{18}$, no cabe duda de que

17 Bustamante García, 1995: 307, nota 10. Carta de Marcantonio Colonna a Mateo Vázquez de Leca, Palermo 29 de abril de 1583, Instituto de Valencia de Don Juan (IVDJ), Envío 54, Caja 71, fol. 44.

18 De 1569 a 1571 Pulzone había estado formando parte de la casa del duque, recibiendo regularmente "parte, $e$ provisione" (la expresión procede de BAGLIONE, 1642: 136, a propósito de la protección que acordó a Caravaggio el cardenal Del Monte): NicOLAI, 2006: 297 y 307-309, doc. 3.

Arch. esp. arte, LXXXv, 340, octUBRE-DiCIEMBRE 2012, 303-328, ISSN: 0004-0428 
el verdadero autor del regalo fue el mismo comitente, quien no sólo quiso agradecer el constante apoyo recibido hasta entonces sino también favorecer la carrera del único hijo que le había quedado tras los tempranos fallecimientos del primogénito Fabrizio y del otro varón Federico. Así, pues, el cuadro tomó el camino de Madrid directamente de Palermo en la primavera de 1583: lo que no impide que la entrega material en manos del secretario, según relata Pacheco, fuera efectuada por Ascanio, posibilidad del todo verosímil al encontrarse éste en contacto directo con la corte. Tampoco era la primera vez que el virrey se proponía entregar a Vázquez un presente adecuado para su posición en la casa del rey. Ya el verano anterior había decidido enviarle un escritorio para su nuevo despacho, pero recibió un rechazo rotundo en cuanto el integérrimo secretario, conforme a sus costumbres y aún más en consecuencia de las rigurosas medidas moralizadoras que siguieron la caída en desgracia en 1579 del rival Antonio Pérez, quería evitar que regalos parecidos pudiesen levantar sospechas sobre su lealdad ${ }^{19}$ : y la sucesiva aceptación de la Subida al Calvario tiene que ser un fuerte recordatorio para que no nos hagamos demasiadas ilusiones sobre el valor relativo de las pinturas en el multiforme ámbito de los objetos suntuarios, al menos anteriormente a la transformación radical del coleccionismo de arte a comienzos del siglo XVII.

Acerca de las relaciones personales entre el duque y el secretario, no es menos interesante llamar la atención sobre la absoluta falta de altivez con que Colonna, apenas dos meses antes de enviar el cuadro de Pulzone, manifestó su felicitación a Vázquez, cuyos orígenes eran como mínimo inciertos, por haber tenido noticia de que éste compartía su misma ascendencia: lo que muestra una inesperada anulación de las diferencias sociales que explica mucho sobre los equilibrios en las relaciones entre corte y periferia en tiempos de los Austrias mayores, aun cuando afectaba la más alta aristocracia. En efecto, los genealogistas encargados de demostrar la limpieza de sangre y los nobles orígenes necesarios para garantizar y afianzar la posición que Vázquez ocupaba en la corte habían alegado su descendencia en línea directa de nada menos que Ugo Colonna, gobernador y conde de Córcega a finales del siglo IX: y es por esta razón que en los antiguos papeles el apellido "Colona" se encuentra a veces añadido a Vázquez de Leca ${ }^{20}$.

El pronto envío de la Subida al Calvario a España limita a menos de dos años la permanencia del cuadro en Palermo, y en cualquier momento habría tenido lugar su envío desde Roma. No es dado conocer la eficacia del recordatorio que el agente Villa hizo el 19 de mayo de 1581, pero es un hecho que la fecha coincide con el año de ejecución referido por Pacheco. Por otro lado, ninguna deducción es autorizada por el pago del 16 de mayo de 1583, al considerar el retraso de hasta años con que esos finiquitos podían efectuarse: para permanecer en el ámbito de la obra de Pulzone, un ejemplo válido es el saldo de cien escudos que el artista cobró en 1593 por la Crucifixión de la capilla Caetani en Santa María en Vallicella, pintura que estaba colgada en el altar desde la primavera de $1586^{21}$. En todo caso, la temprana salida de Sicilia del lienzo de Pulzone permite descartar definitivamente la hipótesis, mantenida alguna vez en la interminable literatura sobre Caravaggio, de que el artista hubiese podido verlo durante su estancia en la isla entre 1608 y 1609, para servirse de él como referencia a la hora de realizar el mismo episodio -el único que se sabe llevó a cabo y en el que seguramente estuvieran representadas figuras de

19 Carta de Diego de Ibarra a Mateo Vázquez de Leca, Madrid 18 de agosto de 1582, IVDJ, Envío 71, Caja 97, fol. 566, en la que el autor se lamenta de esta decisión: GonZALo SÁnCHEZ-Molero, 2005: 841. El mismo autor, 2005: 834-846, al igual que Bustamante García, 1995: 307-308, se detiene en las alhajas y objetos que el secretario se procuró en España e Italia para decorar su despacho y aposento, entre los cuales había algunas pinturas desgraciadamente anónimas.

${ }^{20}$ Lovett, 1977: 3-9, y nota 23. Carta de Marcantonio Colonna a Mateo Vázquez de Leca, Palermo 14 de febrero de 1583, IVDJ, Envío 57, Caja 76, fol. 110. Sobre los oscuros orígenes de Vázquez se explaya Poole, 1999: 382-388.

21 Dern, 2003: 56-58 y 137-140, núm. 39. Parlato, 2009: 144-145. Amendola, 2010: 32. 
medio cuerpo- en la serie de las cuatro historias de la Pasión de Cristo que le fueron encargadas "a capriccio del pittore" en el verano de 1609 por parte del mercader mesinés Niccolò di Giacomo, quien en una célebre nota manuscrita describió el cuadro como un "Christo colla croce in spalla, la Vergine Addolorata e dui manigoldi uno sona la tromba" 22 . Asimismo no es posible que Caravaggio lo hubiese admirado en Roma en casa de los Colonna, familia bajo cuya protección se quedó durante toda su vida.

La descripción en el Arte de la pintura halla exacta correspondencia en el cuadro que hoy vuelve a la luz, y cuyo recorrido desde la Sevilla de la mitad del siglo XVII hasta la Lombardía de nuestros días por el momento permanece desconocido. Mientras que las medidas, aunque perfectamente conformes en las proporciones, resultan aproximadas por defecto respecto a las reales de $120,5 \times 165,5 \mathrm{~cm}$-al corresponder una vara castellana a $83,59 \mathrm{~cm}$, cinco cuartas equivalen a $104,5 \mathrm{~cm}$ y siete cuartas a $146,5 \mathrm{~cm}-$ los detalles de la écfrasis de Pacheco no dejan duda alguna sobre la identidad de la imagen, a partir de los personajes de medio cuerpo y su identificación y disposición en la historia representada, para continuar con el tema dominante de las miradas cruzadas e intensamente expresivas de Cristo y la Virgen y, sobre todo, con la esmerada descripción de los pormenores subrayada por el sevillano, en particular los ojos, los pelos de la barba y las manos del Salvador, como también la mimesis del madero de la cruz que él lleva a cuestas. Tras la reciente limpieza, estos aspectos todavía pueden apreciarse gracias al buen estado de conservación del lienzo, si bien la superficie pictórica aparece empobrecida debido a la ablación de parte de las veladuras, como por ejemplo en correspondencia de las manos de la Virgen en las que apenas pueden detectarse las uñas. Mucho mejor se han mantenido las manos de Cristo, con los efectos de la piel de clara inspiración ticianesca, la barba del mismo, realizada según la costumbre del autor con pinceladas muy sutiles de color ocre claro sobre una base de tierra de Siena, y la figura del sayón de espaldas que en primer plano tira de la soga a la que anda atado Jesús, con su cinta de cuero rojo en bandolera y la camisa con la manga enrollada y el borde del cuello labrado con sobriedad, un detalle que aparece no pocas veces en la obra de Pulzone. En tanto que el manto azul oscuro de la Virgen podría contener partes de lapislázuli, la paternidad del artista se revela especialmente en las típicas tonalidades de algunos colores, por ejemplo la vestidura roja del Salvador y el chaleco amarillento del citado sayón, y en los rostros de las pías mujeres, que se asemejan de cerca a los óvalos alargados, casi siempre inclinados patéticamente y con los rasgos marcados y los labios entreabiertos, que pueblan las obras religiosas del artista de los años setenta y ochenta.

En lo que atañe a la datación, la Subida al Calvario puede cotejarse con la juvenil y todavía verde Salomé recibiendo la cabeza de san Juan Bautista ya Cumming, obra firmada y fechada en 1571 y estrictamente derivada del cuadro del mismo tema de Bernardino Luini en los Uffizi ${ }^{23}$. Obsérvense el ceño del verdugo y los rostros de Salomé y la sirvienta, esta última concebida de manera muy similar a la Magdalena de la más madura y compleja pintura para Marcantonio Colonna, y asimismo la anatomía de los brazos y su disposición paralela a la superficie en primer plano. Sin embargo, los mejores términos de comparación se hallan en el maltrecho, pero menos repintado de lo que suele mantenerse, Martirio de san Juan Evangelista que Pulzone ejecutó para el altar de la capilla Carafa en la iglesia de San Domenico Maggiore en Nápoles, obra cuya colocación tradicional a 1584 es correcto adelantar de varios años ${ }^{24}$ : lo que confirma que todavía

22 En ausencia de novedades concretas desde que en 1907 se dio a conocer el apunte en el que Niccolò di Giacomo comentaba que Caravaggio tenía "il cervello stravolto" (Macioce, 2010: 255, doc. 876), vale reenviar a SPAGNOLO, 2004: 84-85, y Marini, 2005: 90-91, núm. 102, y 582, núm. P-24.

23 Dern, 2003: 4-25 y 96-97, núm. 7. Actualmente el cuadro se encuentra en una colección particular de Módena.

24 Anteriormente se suponía una datación en 1584, al creer que Pulzone viajó a Nápoles a finales de aquel año tanto para entregar a la viuda Felice Orsini un ejemplar del retrato del recién fallecido Marcantonio Colonna (véase la 


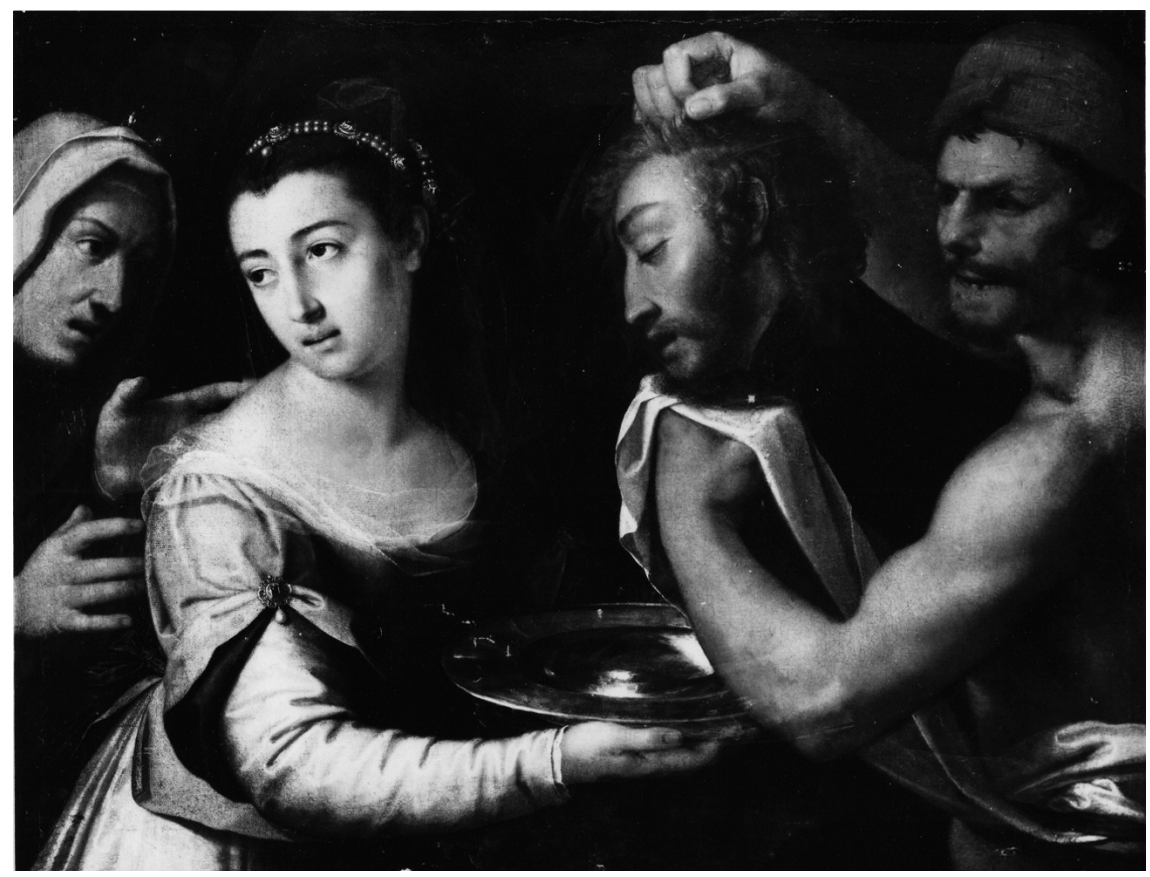

Fig. 10. Scipione Pulzone. Salomé con la cabeza de san Juan Bautista. 1571. Módena, colección particular (Foto Christie's, Londres).

alrededor de 1580 el artista no había resuelto abandonar su primera manera para adoptar del todo el estilo luminoso y brillante al que ha quedado ligada su fama en la posteridad. En los verdugos de catadura popular del gran lienzo napolitano es dado ver los mismos bíceps braquiales y camisas con las mangas enrolladas que caracterizan el sayón de espaldas en la Subida al Calvario, cuyo chaleco de piel se dobla con los mismos efectos de claroscuro que caracterizan el pantalón del hombre arrodillado para atizar la hoguera debajo la caldera de aceite hirviendo en la que está sumergido el Evangelista.

Pero la anterior Salomé ya Cumming, estrictamente derivada de un conocido modelo de Bernardino Luini, se demuestra el parangón más cercano para la Subida al Calvario también a nivel de composición, puesto que la pintura que aquí se da a conocer es una clara evolución de ella, obtenida a través de una considerable ampliación del espacio tanto en vertical cuanto sobre todo en profundidad. Y a la tradición véneta y lombarda del Renacimiento, conectada a su vez con tipologías nórdicas difundidas por medio de las estampas, se inspira en efecto la construcción de la pintura, cuadro de historia centrada en un episodio de la Pasión con personajes de medio cuerpo, entre los cuales destacan verdugos de rasgos cargados que por un lado parecen reenviar a la herencia leonardesca - cuyas trazas afloran periódicamente en la cultura figurativa de la Italia meridional, de la que la formación artística de Pulzone está permeada- y por otro, con mayor

correspondencia en DERN, 2003: 205-207, docs. 12-13) como para retratar a don Juan de Austria, según recuerda sin indicar fechas Baglione, 1642: 53. En realidad don Juan se había marchado camino de Flandes ya en 1576 y había muerto dos años después; además, el perdido retrato del "Sig. Don Giovanni d'Austria" ya está citado en BorghINI, 1584: 578. Sobre el Martirio de san Juan Evangelista, recordado en la literatura a partir de De DoMINICI, 1743: 172, véase DERN, 2003: 34-36 y 97-98, núm. 8, que más acertadamente propone una fecha hacia 1573, en coincidencia con el retrato de don Juan. 
evidencia, al realismo del arte clásico de época imperial, revivido en obras fundamentales de la mitad del siglo como la serie de los once Césares de Tiziano.

Por la manera de afrontar el tema evangélico, la pintura viene a encuadrarse en el importante fenómeno de revival del arte de Sebastiano del Piombo que se propagó en el ambiente romano durante las últimas dos décadas del siglo XVI, del que más bien constituye un incunable ${ }^{25}$. Como es universalmente reconocido, había sido el propio Sebastiano del Piombo quien había difundido en Roma, y desde allí en España y en el resto de Italia, la idea original de Cristo con la cruz a cuestas concebida por Giovanni Bellini, tras haberla hecha moderna enriqueciéndola de un nuevo y profundísimo pathos comenzando por el célebre lienzo hoy en el Prado, pintado antes de 1521, pero probablemente ya hacia la mitad de los años diez, para el embajador Jerónimo Vich y Valtierra, donde Cristo, ante un fondo de paisaje con figuras de reducido tamaño, es socorrido por el Cirineo, a cuyas espaldas se asoma la cabeza de un soldado con armadura ${ }^{26}$. Es cierto que cuando el reinado de papa Gregorio XIII se acercaba a su conclusión ya trabajaba en Roma desde hacía más de treinta

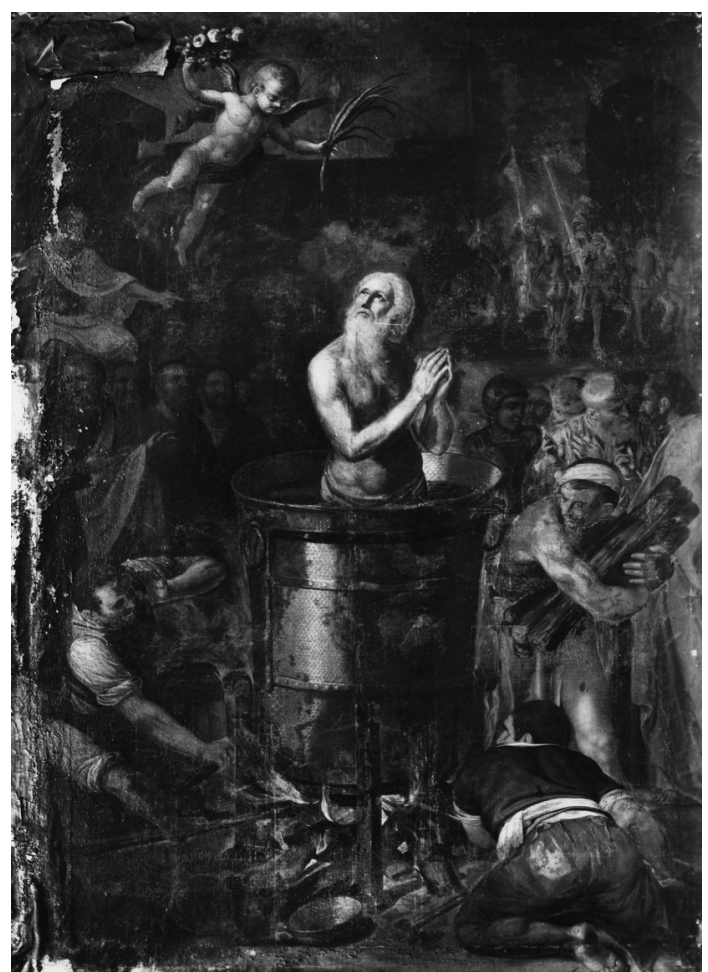

Fig. 11. Scipione Pulzone. Martirio de san Juan Evangelista (antes de la restauración). Hacia 1573. Nápoles, San Domenico Maggiore (Foto Soprintendenza S.P.S.A.E., Nápoles). años Girolamo Muziano, natural de Brescia pero véneto de formación, quien entre muchas otras contribuciones a la pintura de su tiempo había vuelto a proponer el viejo modelo de Sebastiano del Piombo, combinándolo con motivos derivados de Tiziano, en su Cristo con la cruz a cuestas de la Galería Nacional del palacio Barberini. A esta pintura, quizás la misma realizada en 1561 para el cardenal Ippolito de Este, seguramente Pulzone debió de mirar por el guiño y la cabeza ceñida de blanco del leonardesco verdugo a la izquierda ${ }^{27}$. En todo caso, un papel no menos determinante para la recuperación de la fortuna del artista veneciano tuvo que jugarlo el regreso a Roma en 1582, tras muchos años de ausencia y justamente mientras Pulzone resolvía llevar a cabo el lienzo para Marcantonio

${ }^{25}$ Aparte de las varias intervenciones de Strinati (por ejemplo 1999: 115-129), sobre la fortuna de Sebastiano en la edad de la contrarreforma véase PASTI, 2008: 59-65.

${ }^{26}$ El comitente de Cristo con la cruz a cuestas y el Cirineo fue identificado por BenITo DomeneCH, 1988: 5-28. Véase además Benito Domenech, 1995: 41-79. Mena Marqués, 1995: 95-104, núm. 5. Lucco, 2008: 150-151, núm. 24. Posteriormente, Sebastiano representa a Cristo solo en la versión en pizarra de 1537 para el embajador Fernando Silva, conde de Cifuentes, hoy en San Petersburgo, como también en la de Budapest, de hacia 1540 e insegura procedencia (Contini, 2008: 238-239, núm. 60 y 244-245, núm. 63, con bibliografía). Variante de esta es el lienzo de la Galería Borghese, cuya autoría es aún objeto de debate entre Sebastiano del Piombo y Giovanni de' Vecchi, en el que Cristo figura en compañía de la Virgen: ConTini, 2008: 244, núm. 63. Mantiene la atribución al veneciano HerRMANN FIORE, 2005: 33-74.

27 Tosini, 2008: 157-164 y 348-349, núm. A13. 


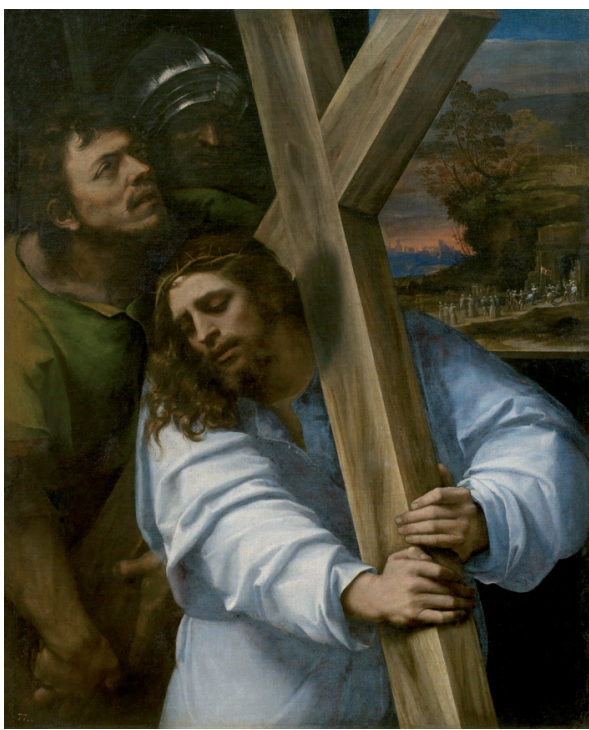

Fig. 12. Sebastiano del Piombo. Cristo con la cruz a cuestas y el Cirineo. Hacia 1516. Madrid, Museo Nacional del Prado (Foto Museo).

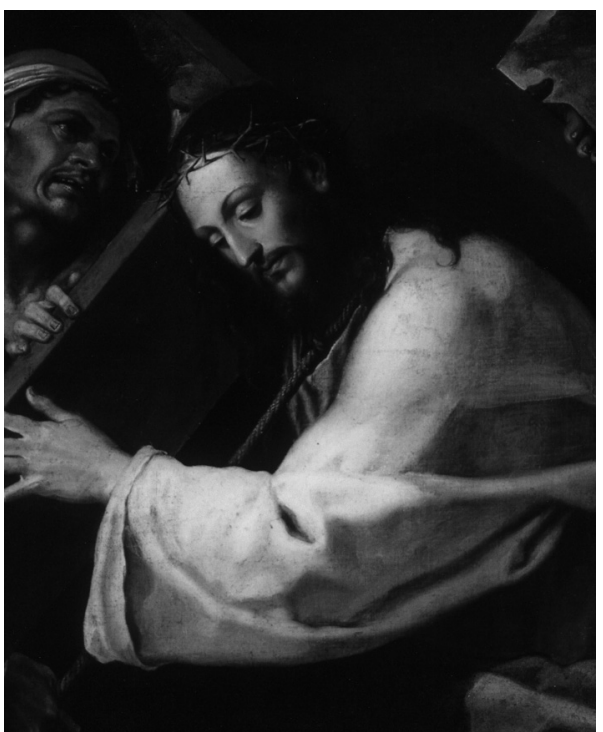

Fig. 13. Girolamo Muziano. Cristo con la cruz a cuestas. ¿1561? Roma, Galleria Nazionale d'ArteAntica (Foto Soprintendenza S.P.S.A.E., Roma).

Colonna, del palermitano Tommaso Laureti. Como relata Vasari, de joven Laureti habría tenido tiempo de ser discípulo de Sebastiano del Piombo, quien falleció en junio de $1547^{28}$, y gracias a una anónima guía manuscrita de comienzos del siglo XVII consta que en el coro de la iglesia de San Bernardo alle Terme -cuyos altares laterales alojaban dos celebrados retablos de su mano, realizados entre 1598 y 1602 - colgaba un "Christo che porta la croce" suyo, igualmente perdido, cuya relación con la obra de Pulzone es imposible determinar ${ }^{29}$.

Como Pacheco sabía muy bien, el núcleo dramático de la composición de Pulzone -formado por el intenso intercambio de miradas entre Jesús y su Madre, a la que acompañan la Magdalena y san Juan Evangelista- traía su origen del LXV capítulo de las populares Meditationes vitae Christi del Pseudo-Buenaventura, a su vez compuesto a partir del renglón correspondiente del Evangelio de Lucas"30: "Quia Christo propter multitudinem gentium mestissima mater appropinquare nequibat, ivit per aliam viam breviorem celeriter cum Iohanne et sociabus ut alios precedens ei appropinquare posset. Cum autem extra portam civitatis ex concursu viarum eum habuit obvisum, cernens eum sic oneratum ligno tam grandi semimortua est pre angustia nec ei verbum dicere potuit nec Dominus illi, acceleratus ab eis qui eum ad crucifigendum ducebant. Ulterius parum procedens vertit se ad mulieres flentes dicens: Filie Hierusalem nolite flere super

28 VASARI (1568), 1906: Vol. V, 585-588. Sobre Laureti (Palermo 1525-Roma 1602) en calidad de pintor: BAGLIONE, 1642: 72-73. GRASSo, 2005: 84-88. NiCOLAI, 2011: 394-397. MaZzola, 2011: 107-110.

${ }^{29}$ El cuadro está citado en la guía de la Biblioteca Casanatense de Roma (ms. 4168), fechable entre 1615 y 1622 : DORATI DA EMPOLI, 2000: 27.

${ }^{30}$ Lc XXIII, 27-28: "Sequebatur autem illum multa turba populi, et mulierum quae plangebant et lamentabantur eum. Conversus autem ad illas Iesus, dixit: Filiae Ierusalem, nolite flere super me, sed super vos ipsas flete, et super filios vestros". 
me, sed super vos et super filios etc." "31. Naturalmente, en el ámbito de la pintura de historia el imprescindible arquetipo de la moderna tradición iconográfica del episodio es el Pasmo de Sicilia de Rafael, prontamente grabado en 1517 por Agostino Veneziano, donde el tema del diálogo de miradas y gestos entre Jesús y María, juntado en unidad de acción con el de la caída del Hijo bajo el peso de la cruz, ya constituye el centro dinámico alrededor del que se desarrolla la compleja multiplicidad narrativa de la imagen ${ }^{32}$. Cambiados los tiempos y el destino de la pintura, en su caso privado, Pulzone decidió abolir, con objeto de buscar la máxima fidelidad al texto medieval de las Meditationes conforme a las más modernas exigencias filológicas de la Contrarreforma, cualquier alusión al momento de la caída: y es por esta razón que eligió valerse de la afortunada tipología contemplativa y devocional de Cristo con la cruz a cuestas que Sebastiano del Piombo había introducido en Roma más de sesenta años antes, en cuyas numerosas réplicas, variaciones, copias y derivaciones nunca figuraba más de un único personaje reconocible iconográficamente aparte del Salvador y tampoco tenía lugar algún intercambio de miradas ${ }^{33}$.

Independientemente de Pulzone, respectivamente antes y después de su interpretación la matriz rafaelesca se puso en discusión en Roma, en ambos casos en público y amplio formato vertical, por Livio Agresti en el Oratorio del Gonfalone, en un fresco de la serie de la Pasión ejecutado en $1571^{34}$, y por Federico Zuccari en la tabla para el altar de la capilla Olgiati en la iglesia de Santa Prassede, realizada en 1595 reelaborando de manera significativa la pintura hecha unos ocho años antes para el retablo mayor de la basílica de El Escorial ${ }^{35}$. En efecto, el renovado culto postridentino a las reliquias indujo a reconsiderar un aspecto que ya se veía representado, pero permaneciendo Jesús de pie, en aquel precocísimo reflejo de la devotio moderna que es la estampa de finales del siglo XV de Martin Schongauer, como también, sin dejar aparte el grabado de Lucas van Leyden de 1521, en las xilografías de la Pasión Grande y Pequeña de Durero, de 1499 y 1509 respectivamente, todas estas mostrando al Salvador caído y siendo la de 1499 la más directa fuente de inspiración no solo para la composición del mismo Rafael sino también para la escena de masa de Agresti ${ }^{36}$ : es decir, la pérdida de preeminencia de la Virgen en favor de la Verónica sujetando el pañuelo, figura que en el cuadro de Zuccari en Santa Prassede - tras haber sido omitida, a la par de la Virgen, en la pintura de El Escorialincluso llega a asumir el papel de coprotagonista. Pero lo que viene a faltar en las imágenes de Agresti y Zuccari es sobre todo el elemento comunicativo, puesto que en ellas Jesús, caído de rodillas, tiene la mirada dirigida al suelo.

Inmediatamente después de la pintura de Zuccari, una nueva evaluación crítica del modelo rafaelesco, esta vez en sentido invertido respecto al original, se encuentra en la febril composición sobre lienzo, de extenso encuadre y formato horizontal, que Gaspare Celio pintó entre 1596 y 1597 para la pared izquierda de la capilla de la Pasión, de patronato de los Mellini, en iglesia del Gesù de Roma ${ }^{37}$. Pero a la luz de la estrecha concentración espacial de afectos que acerca entre sí el Cristo, la Virgen, la Magdalena y el Evangelista, mientras que la apócrifa Verónica ha desaparecido de la historia, parece lícito suponer que Celio haya podido sacar inspiración

31 Se cita de la edición de Petit, hacia 1497: s.p. La puntuación y el uso de las mayúsculas se han modernizado.

32 Ruiz Manero, 1996: 61-69. Henry y Joannides, 2012: 94-102, núm. 4. Todos los personajes que toman parte en el episodio según las distintas tradiciones, pero cada cual representado por su cuenta casi en forma de Via Crucis, aparecen incluidos en la gran tabla manierista de Polidoro da Caravaggio en Capodimonte, pintada antes de 1534 para la Anunciación de los Catalanes en Mesina: LeONE DE CASTRIs, 2001: 343-355.

33 En este sentido puede aplicarse perfectamente la tesis del libro de RinGBOM, 1965.

34 Bernardini, 2002: 66-73.

35 ACIDINI LuCHINAT, 1999: 160-164 y 180-181. StOENESCU, 2011: 423-448.

${ }^{36}$ De los grabados de Durero y Lucas van Leyden deriva, pasada la mitad del siglo, la estampilla de Giulio Bonasone, cuya serie de la Pasión influyó considerablemente sobre la decoración del Oratorio del Gonfalone.

37 HibBARD, 1972: 44. 


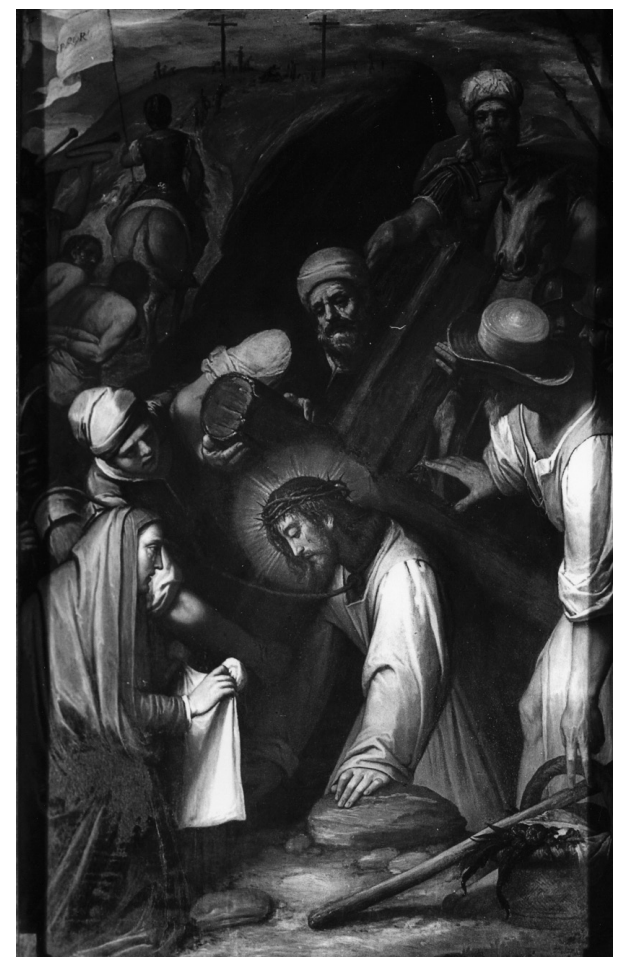

Fig. 14. Federico Zuccari. Subida al Calvario. 1595. Roma, Santa Prassede (Foto Soprintendenza S.P.S.A.E., Roma).

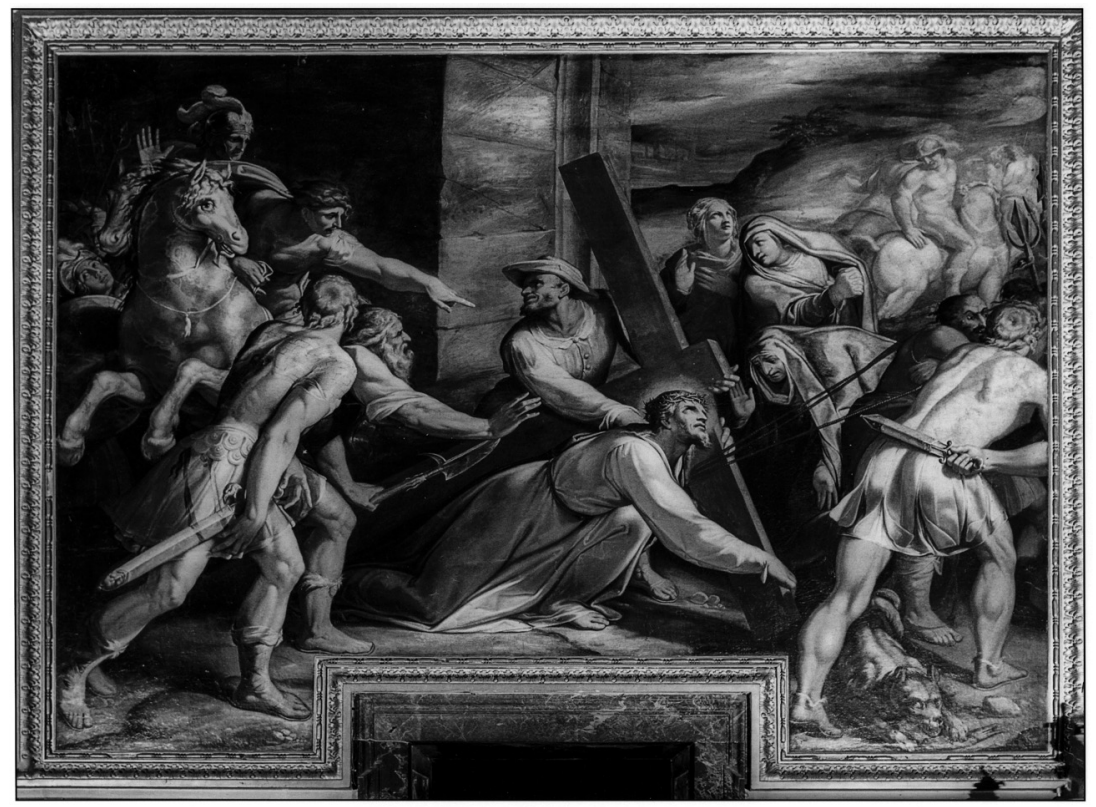

Fig. 15. Gaspare Celio. Subida al Calvario. 1596-97. Roma, Gesù (Foto Soprintendenza S.P.S.A.E., Roma).

Arch. esp. arte, LXXXv, 340, octUBRe-DICIEMBRe 2012, 303-328, ISSN: 0004-0428 
también de la más reciente obra de Pulzone, quien para la misma capilla había proporcionado entre tanto la tabla del altar con la Piedad, fechada probablemente en 1593, hoy en día en el Metropolitan Museum de Nueva York ${ }^{38}$. Debido a un comprensible condicionamiento contextual, se ha querido sostener que la invención de Celio procede del correspondiente grabado de las Evangelicae historiae imagines del padre Jerónimo Nadal, impresas en 1594 ${ }^{39}$ : sin embargo, en la estampa cualquier margen para los sentimientos ha sido anulado a favor de una sorda y enteramente jesuítica escena de violencia en la que Jesús, el único personaje identificable, queda en pie y aparece rodeado por una turba de soldados sin nombre, en neta contraposición con el sentimentalismo patético de las franciscanas Meditationes.

En un sentido expresivo análogo al del grabado, pero por el camino de una lóbrega atmósfera cargada de angustia y crueldad, procede la otra y mucho más grande representación de la Subida al Calvario que los jesuitas de Roma patrocinaron con motivo del año jubilar de 1600. Se trata del tétrico y agobiante fresco de Andrea Commodi en la media naranja del ábside de San Vitale, donde el sadismo y el horror llegan al tope en la imprevisible sustitución del que habría debido ser el Cirineo con un personaje de aspecto diabólico ${ }^{40}$. Y a propósito de la obra de tamaño monumental de Commodi, merecería reflexionar más detenidamente sobre la absoluta desatención -en tiempos de Contrarreforma, caso raro y clamoroso de falta de respeto hacia los requerimientos del patronato eclesiástico- de los desiderata que en agosto de 1599 el general de la Compañía, padre Claudio Acquaviva, manifestaba en estos términos a Giovan Battista Fiammeri, superintendente de la decoración, en evidente sintonía con el texto de las Meditationes y la invención rafaelesca exhumada por Celio en el Gesú: "gusterei che la Madonna S.ma e l'altre Marie fussero intere e che venissero incontro al Signore, il quale riguardasse la madre, et ella lui, con affetto" 41 .

Un corte restringido no lejano del que caracteriza la pintura de Pulzone, y posiblemente inspirado a ella, vuelve a verse más tarde, hacia 1607, en el lienzo de devoción particular de Orazio Gentileschi actualmente en Viena, donde el artista pisano, consciente del prototipo de Sebastiano para la figura del Cristo encorvado llevando la cruz, modifica una vez más la iconografía del episodio y, verosímilmente a instancia de los comitentes, viene a atribuir el otro papel principal a la Magdalena, pero sin que las miradas de los dos protagonistas se crucen. A su vez, la Virgen es empujada hacia atrás y adosada al margen derecho y presenta la faz casi totalmente escondida por el manto lapislázuli, casi como Agamenón en el Sacrificio de Ifigenia de Timantes según la descripción de Plinio el Viejo ${ }^{42}$. Además Gentileschi, reducidos a dos los sayones y bloqueada la acción por medio de una luz más naturalista de taller que realmente natural, acrecienta la monumentalidad sobrecogedora de la escena bajando considerablemente el punto de vista y proyectando así las figuras contra el cielo azul surcado de nubes, debajo del que se extiende el perfil desnudo de la montaña del Gólgota ${ }^{43}$. Queda finalmente por investigar, pero es tarea que sobrepasa los límites de la presente contribución, la influencia que sin duda la pintura de Pulzone tuvo que ejercer a su llegada a España, a partir del famoso Encuentro de Cristo con la Virgen, hoy en el Museo de Bellas Artes de Valencia, que Francisco Ribalta pintó a comienzos de la segunda década del siglo XVII para el monasterio de San Miguel de los Reyes de la misma

38 DERN, 2003: 75 y 162-163, núm. 54

39 Bailey, 2004: 327-328, núm. 80.

40 ZuCCARI, 1984: 142. BaILEy, 2004: 173. PAPI, 2012: 26-28 y 71-83.

41 BAILEY, 2004: 327-328, núm. 80.

${ }^{42}$ Naturalis Historia, XXXV, 73.

${ }^{43}$ Christiansen, 2001: 58-61, núm. 5, quien nota la contradicción entre "la luce tagliente, "da illuminazione di cantina", e l'ambientazione all'aperto". El lienzo, en Viena desde 1800, procede de la colección Albani de Roma.

Arch. esp. arte, LXXXv, 340, octUBRE-DiCIEMBRE 2012, 303-328, ISSN: 0004-0428 
ciudad y cuya mitad derecha, como es sabido, está copiada del lienzo de Sebastiano del Piombo, entonces propiedad de don Álvaro Vich ${ }^{44}$.

Antes de concluir este artículo, conviene preguntarse de qué modo artistas como Laureti, Celio y Gentileschi, para no hablar de Caravaggio, pudieron reflexionar sobre la obra de Pulzone, puesto que ella permaneció en Roma por muy poco tiempo tras ser entregada, y además bajo estricto control por causa de la ausencia de su legítimo propietario: seguramente no más de unas pocas semanas, si no solamente los días necesarios para que se secaran las barnices. Una vez más, las fuentes impresas y de archivo ofrecen la respuesta, puesto que en ellas se da noticia de una segunda versión, algo diferente en el tamaño y el formato, de la Subida al Calvario. En las primeras aparece citada como obra de Pulzone a partir de 1620, cuando Celio la recuerda en la Villa Medici en el Pincio como "la pittura del Christo, che porta la Croce, mezze figure, sopraporto, di Scipione Caetano" 45 , pero la mención más antigua, sin nombre de autor, está contenida ya en el inventario de bienes del cardenal Ferdinando de' Medici, redactado en 1588 a la hora de su traslado a Florencia como nuevo gran duque de Toscana: "1 quadro grande in tela di Cristo che porta la + [es decir, la cruz] con la Madonna Marie et farisei con ornamento nero tocco d'oro". En el mismo lugar, y casi toda vez reconocida como pintura de Pulzone, se encuentra en los sucesivos inventarios de 1598, 1602, 1623, 1670,1671, $1680 \mathrm{y}$, transferida al palacio Madama, $1740^{46}$. A partir de entonces de ella también se pierden las huellas, pues no tiene valor alguno, al tratarse claramente de una información sacada de las anteriores guías de Roma, la última cita en la Villa Medici que proporciona Roisecco en $1765^{47}$. Los mismos inventarios indican las medidas del cuadro en tres palmos romanos por seis y tres cuartos, que confirman su carácter de sobrepuerta como relatan las guías y corresponden a 67 por $150 \mathrm{~cm}$ : por lo que queda fuera de discusión una eventual identidad con el cuadro objeto de esta publicación.

Los datos de los inventarios permiten ya suponer que esta segunda versión hubiera sido realizada por encargo del cardenal de' Medici poco tiempo después de ejecutarse el prototipo. No hay razón para negar que se tratase de una réplica autógrafa, puesto que no sólo Pulzone solía repetir sus obras de buena gana, sino que también resulta trabajar desde 1568 para el purpurado, al que en 1580 había pintado un magnífico retrato de cuerpo entero, adquirido en 1998 por la Art Gallery of South Australia de Adelaide ${ }^{48}$. La hipótesis puede ser confirmada gracias a una carta que Ottaviano Villa envió al virrey Marcantonio Colonna el 15 de mayo de 1583, es decir, aproximadamente tres semanas después de que el original de la Subida al Calvario hubiera sido embarcado para España y apenas cuatro días después de recibir Pulzone el saldo de 200 escudos. En la carta el agente del duque, tras informarlo que el pintor había "rimasto soddisfattissimo" del generoso pago, añadía que "il Sig. Cardinale di Medici ha fatto fare un essempio del detto quadro et disse a Scipione l'altro hieri che li dicesse se V[ostra] E[ccellenza] haveva mandato il suo in Spagna et che non ne li seppe dar altra nova; Scipione mi ha detto che crede certo il cardinale mandarà questo suo quadro in Spagna"49. De hecho, el cardenal de' Medici al que hace referencia Villa no puede ser otro que Ferdinando y no, como se ha creído, Alessandro, futuro papa León XI, al que se otorgaría el capelo no antes del siguiente 12 de diciembre ${ }^{50}$. Pero mucho más

${ }^{44}$ Benito Domenech, 1995: 66-68. Falomir, 2008: 368-369, núm. 121.

45 Celio (ms. 1620, 1638), 1967: 42(138) y 103, nota 399: "La pittura del Christo, che porta la Croce, mezze figure, sopraporto, di Scipione Caetano". De aquí MARTINELli (ms. 1660-1663), 1968: 321: "La pittura del Christo che porta la Croce, mezze figure, sopra porto, di Scipione Gaetano". DERn, 2003: 44, nota 114 y 199, núm. 102.

46 Cecchi y Gasparri, 2009: 86, núm. 87 (187).

47 Roisecco, 1765: Vol. II, 150. Zocca en Celio (manuscrito de 1620, 1638), 1967: 103, nota 399.

48 El retrato, firmado y fechado en 1580, es alabado por BAGLIONE, 1642: 53. CECCHI, 1999: 60 y 136-137, núm. 1. DERN, 2003: 41-42 y 119-120, núm. 26, todavía lo sitúa en paradero desconocido.

49 Nicolai, 2006: 303 y 317-318, doc. 25.

50 Así Nicolai, 2006: 303. 


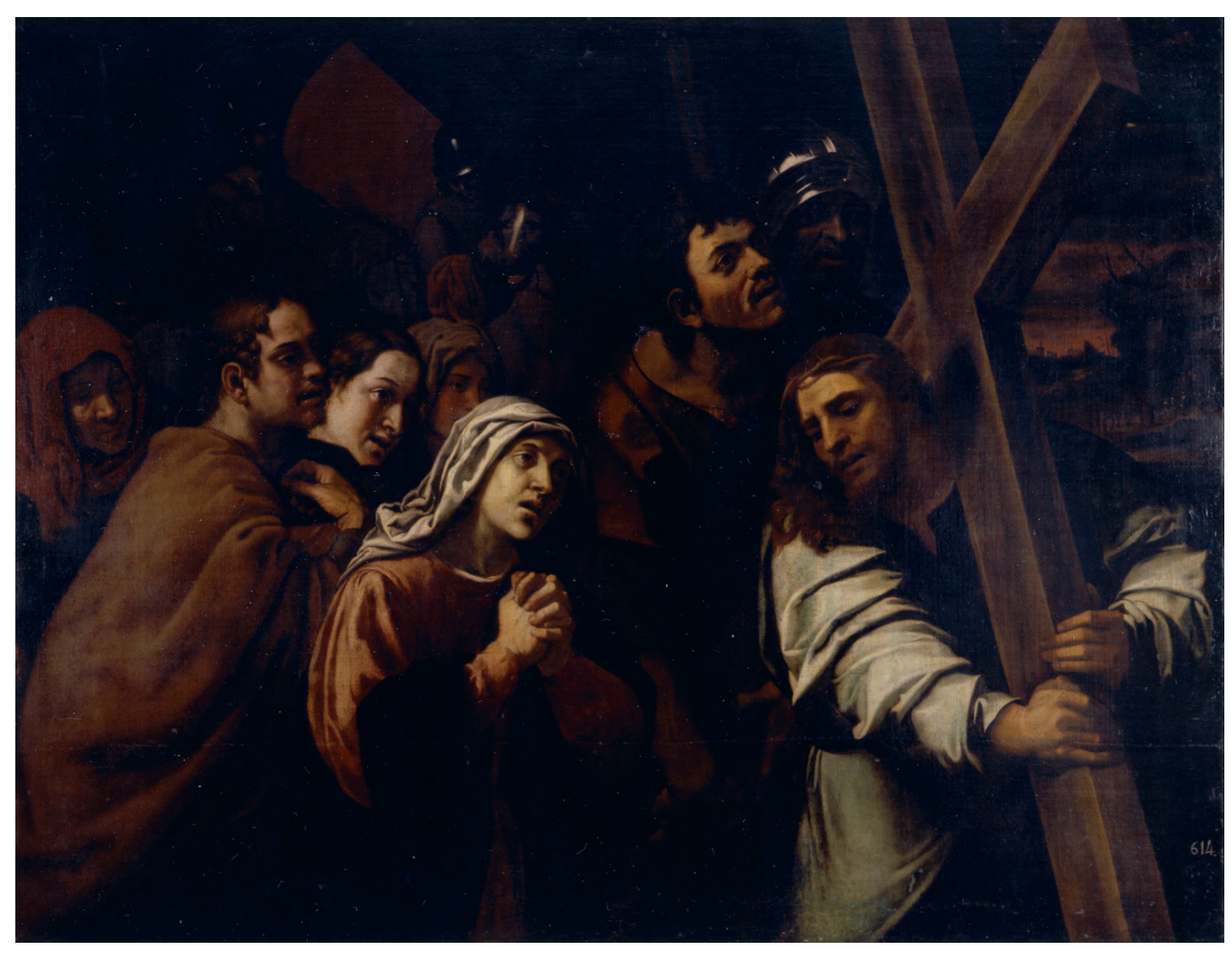

Fig. 16. Francisco Ribalta. Encuentro de Cristo con la Virgen. Hacia 1610-1614. Valencia, Museo de Bellas Artes (Foto Museo).

importante es subrayar que el término "essempio" no debe entenderse como copia sino justamente como "ejemplar", es decir, réplica: como se ha dicho, no hay motivo para creer que el agente del duque se hubiese quedado con el original un día más del necesario y tampoco es imaginable que hubiese consentido a la realización de una copia aún antes de que este llegase a manos de su señor, además informándole por escrito con absoluta indolencia. Asimismo no tiene sentido alguno suponer que Pulzone hubiera encargado a otra persona la ejecución de una copia derivada del modelo gráfico o del boceto pintado que según la costumbre debía guardar en su taller, con mayor razón al ser ésta destinada a uno de sus más destacados mecenas. Y aunque la supuesta copia hubiera sido realizada a escondidas de Scipione, el cardenal de' Medici no le habría hablado tan abiertamente de ella al poco de entregarse el original, puesto que Villa no parece haber tenido noticia de la segunda versión sino gracias al propio autor.

En resumen, Ferdinando de' Medici también se había planteado la idea de mandar a España, seguramente para darlo en regalo a algún miembro de la corte, su proprio ejemplar de la Subida al Calvario, pero por otras vías le había llegado noticia de que Marcantonio Colonna había manifestado, y tal vez llevado a efecto, la misma intención. Por lo tanto, a fin de evitar el envío de una imagen allí ya conocida había llamado a Pulzone para preguntarle si realmente el entonces virrey de Sicilia había realizado su propósito, sin que el pintor supiese darle por el momento respuesta. No obstante, el purpurado debió de tardar muy poco en enterarse de la verdad de la información recibida, pues resolvió no privarse de la réplica y decidió quedarse con ella en su 


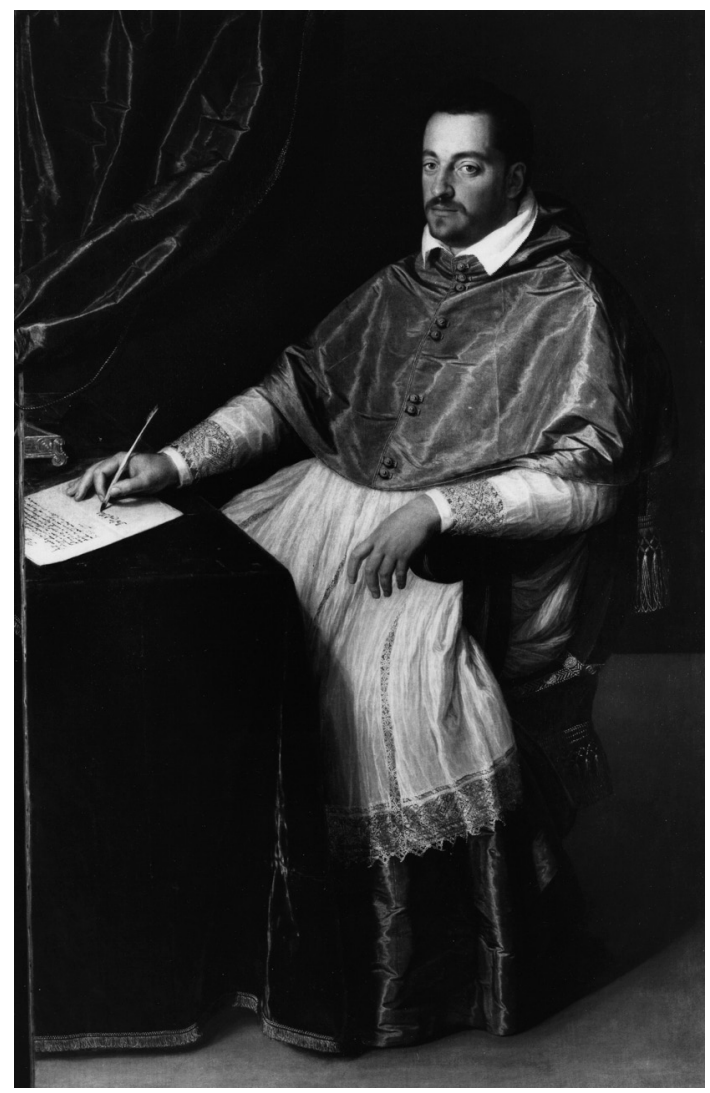

Fig. 17. Scipione Pulzone. Ferdinando de’ Medici. 1580. Adelaide, Art Gallery of South Australia (Foto A.C. Cooper Ltd., Londres).

villa del monte Pincio; consecuentemente acudió a su pintor de confianza, el florentino Jacopo Zucchi, encargándole la ejecución de otra pintura apta para su destino. De hecho, una más atenta lectura de una entrada de inventario contenida en los libros de guardarropa del cardenal no sólo permite seguir el desarrollo de los acontecimientos, sino también el nombre del destinatario del presente: en fecha del 7 de febrero de 1583 estilo florentino, o sea 1584 según el computo común, se anota el ingreso de una pequeña pintura en cobre de mano de Zucchi, de apenas un palmo de largo y representando a "Nostra Donna con Christo in braccio in abito di zingana", que tenía que ser regalada al mismísimo "Secret[ario] Vasches" „51. La lógica concatenación de los eventos deja muy pocas dudas de que Mateo Vázquez era el personaje al que Ferdinando de’ Medici había

51 Archivio di Stato di Firenze (ASF), Guardaroba Medicea (G), vol. 79, Inventario Generale a Capi, fol. 399: "Dua quadrettini in rame uno di p [almo] $i$ incirca dipinto la Nostra Donna con Christo in braccio in abito di zingana e uno simile vestita al ord[inari]o ritratto da una di Michelag[no]lo fattoci m[aestr]o Iacopo Zucchi a di 7 di febbraio 1583, q[uaderno] $J<$ fol. $>27, n .2 . / /$ Dua quadretti in rame in uno dipintovi la Nostra Donna a la zinganescha et l'altro una Nostra Donna che vie'da uno di Michelag[no]lo e fattoli fare li ornamenti d'ebano [en interlínea sopra di nocie rayado] e dati a S.S. Ill. ${ }^{\text {ma }}$ che uno va donato al Secret[ario] Vasches e uno alla Marchesa Santa Croce a di 7 di febbraio 1583, al quaderno $J<$ fols.> 27, 28 [enmendado sobre 65], n. 2". Pillsbury, 1980: 208 y 225, quien leyó "al Secret[ario] Vasches" como "a lucret'vasches". 
proyectado enviar también el lienzo de Pulzone, lo que explica aún mejor la cautela manifestada anteriormente por el prelado, comprensiblemente preocupado de que al secretario no fuese entregada la réplica de un cuadro que acababa de recibir por otras vías.

No cabe duda de que a fuerza de presentes el ambicioso cardenal de' Medici trataba de cautivar el favor del influyente secretario, y a través de él facilitar el trámite para alcanzar y conservar la benevolencia de Felipe II. En efecto, no era ni la primera ni la última vez que el purpurado, y luego gran duque de Toscana, disponía el envío de regalos al rey y a su entorno ${ }^{52}$ : ya el 22 de enero de 1582 se esperaba en Madrid la llegada de dos crucifijos de plata, uno de los cuales tenía que ser puesto en manos del propio $V_{a}$ áquez ${ }^{53}$, y el 13 de febrero de 1583 Giulio Battaglini, agente de los Medici recién llegado a la capital para servir en la secretaría de la embajada, aguardaba instrucciones de parte del cardenal sobre la entrega de algunos objetos de arte a varios personajes de la corte. Además, en el siguiente mes de junio se recibía en Madrid la gran esfera armilar de Antonio Santucci delle Pomarance, ofrecida en regalo a Felipe II y que hoy en día domina el centro de la biblioteca de El Escorial ${ }^{54}$. Finalmente, más de seis años después, cuando Ferdinando de' Medici ya había subido al trono gran ducal, fue Battaglini en persona quien solicitó la rápida realización y el envío de Florencia de un "fonticino" "di marmo fino di Carrara", fuente de la que adjuntaba el diseño y que él mismo tenía prometida una vez más al "religiosissimo" secretario español, tras haber ganado su notoria contrariedad a aceptar en regalo objetos profanos ${ }^{55}$.

Y efectivamente la pequeña pintura de Zucchi, por sujeto y medidas, se prestaba aún mejor que el lienzo de Pulzone a ser acogida por Vázquez como un simple objeto de devoción, coartada que generalmente, tras la despedida de Antonio Pérez, permitía a los funcionarios reales eludir la prohibición de recibir regalos de valor ${ }^{56}$. Tanto por pertenecer a la casa de' Medici y además ser hijo de doña Leonor de Toledo, como por haber asumido el papel de figura de referencia de la facción española en la curia desde su nombramiento como protector de España a comienzos de octubre de 1581, seguramente no faltaban al cardenal razones para cultivar las mejores relaciones posibles con la corona de la que dependía la investidura gran ducal de su familia sobre Toscana; pero en aquel preciso momento cabe preguntarse si uno de sus objetivos no podía ser el de contrarrestar las presiones que, a partir de 1582 o 1583, su hermano el gran duque Francisco I estaba haciendo para que Felipe II aprobara oficialmente la legitimación del hijo natural don Antonio, nacido en 1576 de su todavía amante Bianca Cappello. El reconocimiento de la sucesión por parte del rey habría sepultado para siempre las mal disimuladas aspiraciones dinásticas del cardenal, y el mandato de relatar en tiempo real sobre la marcha de la cuestión había sido el motivo principal de la propia misión de Battaglini en Madrid ${ }^{57}$.

En el intento de cumplir lo más posible con el gusto del destinatario español, a Zucchi se le pidió por lo tanto que trabajara sobre una iconografía de más íntima espiritualidad con respecto a la Subida al Calvario, y sobre todo tan típicamente ibérica como la de la Virgen "in abito di zingana", es decir, alusiva a la huida a Egipto -tierra de la que los gitanos se consideraban

52 Sobre los regalos de arte de Ferdinando de' Medici a España: GoldBerg, 1996: 105-114 y 529-540. MulCAHY, 1998: 179-180. Goldberg, 2003: 115-133. Salort y Kubersky-Piredda, 2006: 660-663. Salort y Kubersky-PiREDDA, 2007: 227.

${ }_{53}$ Carta de Pietro Riccardi a Pietro Usimbardi, secretario del cardenal. Mulcahy, 1998: 180 y 183, nota 62.

${ }^{54}$ Salort y Kubersky-Piredda, 2006: 662. Salort y Kubersky-Piredda, 2007: 227.

55 Cartas de Giulio Battaglini a Pietro Usimbardi, 20 de agosto de 1588, 15 de octubre de 1588 y 7 de enero de 1589. Archivo de Estado de Florencia (ASF), Mediceo del Principato, Vol. 4919, fols. 440, 510 y 652. www.medici.org, The Medici Archive Project.

56 Mulcahy, 1998: 166-169.

57 Mulcahy, 1998: 172. Luti, 2006: 82-86. Luti, 2009: 22-24. Sobre Ferdinando de' Medici como cardenal (Florencia, 19 o 30 de abril de 1549-3 de febrero de 1609): FASANO GuARINI, 1996: 258-278. CALONACI, 2000: 5-74. 
oriundos- y caracterizada habitualmente por un sombrero de paja entrelazada de alas anchas, hasta ser llamada de otra manera la Virgen del sombrero. De esta iconografía eran entonces muy populares las representaciones creadas por Luis de Morales, entre las que las "dos tablas de nra. Señora vestida de gitana con el niño en cada una" que le encargó en 1567 el obispo de Badajoz don Juan de Ribera ${ }^{58}$ : y es interesante observar que la definición, pronto caída en desuso, fuese tan familiar en Italia al cardenal de' Medici y a sus colaboradores que les salió natural emplear en los libros de guardarropa una fórmula idéntica a la utilizada en Extremadura. Por otro lado, puesto que en ninguna de las versiones del Descanso en la huida a Egipto de Zucchi hoy conocidas la Virgen lleva un sombrero de ese tipo o presenta un atuendo menos que tradicional, aun sin considerar la diferencia de medidas es seguro que el paradero del pequeño cobre es actualmente ignoto ${ }^{59}$.

Pero también a propósito de la Subida al Calvario, es imposible no destacar que la completa sintonía del punto de vista de Marcantonio Colonna y Ferdinando de' Medici hacia la imagen que Scipione Pulzone inventó constituye una demostración ejemplar de la amplia y profunda difusión del conocimiento, en la Italia de la Contrarreforma, de las exigencias y predilecciones de los españoles en las artes visuales. Gracias a este conocimiento, ambos pudieron estar seguros no sólo de la aceptación sino incluso del agrado con que se recibiría en los ambientes de la corte ibérica una obra tan imbuida de patetismo devocional, aunque suavizado y actualizado en sentido orvietano con respecto al austero y mudo rigor tanto de los anteriores modelos de Sebastiano del Piombo como de los icónicos pero no menos populares y apreciados "cartonetti" miguelangelescos traducidos a la pintura por Marcello Venusti ${ }^{60}$.

\section{BIBLIOGRAFÍA}

Acidini Luchinat, Cristina, Taddeo e Federico Zuccari fratelli pittori del Cinquecento, Vol. II, Roma, Jandi Sapi, 1999.

Amendola, Adriano, I Caetani di Sermoneta. Storia artistica di un antico casato tra Roma e l'Europa nel Seicento, Roma, Campisano, 2010.

Anselmi, Alessandra, “'Tota pulchra es amica mea et macula non est in te': la Spagna e l'Immacolata a Roma”, en Anselmi, Alessandra (coordinadora), L'Immacolata nei rapporti tra Italia e Spagna, Roma, Gangemi, 2008, pp. 239-300.

Baglione, Giovanni, Le nove chiese di Roma (Roma, Andrea Fei, 1639), edición de Barroero, Liliana, Roma, Archivio Guido Izzi, 1990.

Baglione, Giovanni, Le vite de' pittori scultori et architetti. Dal Pontificato di Gregorio XIII. del 1572. In fino a'tempi di Papa Urbano Ottavo nel 1642., Roma, Andrea Fei, 1642.

Baglione, Giovanni, Le vite de' pittori scultori et architetti. Dal Pontificato di Gregorio XIII. del 1572. In fino a'tempi di Papa Urbano Ottavo nel 1642. (Roma, Andrea Fei, 1642), edición en facsímil de Hess, Jacob, y Röttgen, Herwarth, Ciudad del Vaticano, Biblioteca Apostólica Vaticana, 1995.

Bailey, Gauvin Alexander, Between Renaissance and Baroque. Jesuit Art in Rome, Toronto, University of Toronto Press, 2004.

\footnotetext{
58 Pérez SÁncheZ, 2003: 313-316. Mateo GómeZ, 2007: 7-24.

59 CeCCHI, 1999: 290-293, núms. 80-81.

${ }^{60}$ Sobre la fortuna de Sebastiano del Piombo en España: Benito, 1995: 41-79. FALOMIR, 2008: 67-71. A propósito del estilo orvietano: StRINATI, 1999: 115-129. Tosini, 2008. Sobre la fortuna de Venusti en España: RuIZ MANERO, 1995: 368-372. Sobre el gusto español por la pintura religiosa entre el Renacimiento y la Contrarreforma: MARÍAS, 1989: 220-236 y 584-610. BuSTAMANTE, 1995: 304-308.
} 
Barroero, Liliana, "La Basilica dal Cinquecento ai nostri giorni”, en Pietrangeli, Carlo (coordinador), San Giovanni in Laterano, Florencia, Nardini, 1990, pp. 145-256.

Bazzano, Nicoletta, Marco Antonio Colonna, Roma, Salerno, 2003.

Bazzano, Nicoletta, “Da ‘imperiali’ a 'spagnoli': i Colonna e la política romana da Carlo V a Filippo II”, en Hernando Sánchez, Carlos José (coordinador), Roma y España. Un crisol de la cultura europea en la edad moderna, Madrid, SEACEX, 2007, pp. 281-293.

Benito Domenech, Fernando, "Sobre la influencia de Sebastiano del Piombo en España: a propósito de dos cuadros suyos en el Museo del Prado", Boletín del Museo del Prado, 9, 1988, pp. 5-28.

Benito Domenech, Fernando, "Sebastiano del Piombo y España", en Mena Marqués, Manuela (comisaria), Sebastiano del Piombo y España, cat. exp., Madrid, Museo del Prado, 1995, pp. 41-79.

Bernardini, Maria Grazia, "Il ciclo della Passione di Cristo: gli artisti”, en Bernardini, Maria Grazia (coordinadora), L'Oratorio del Gonfalone a Roma. Il ciclo cinquecentesco della Passione di Cristo, Roma, Silvana, 2002.

Borghini, Raffaello, Il Riposo, Florencia, Giorgio Marescotti, 1584.

Bustamante García, Agustín, "Datos sobre el gusto español del siglo XVI", Archivo Español de Arte, 68, 1995, pp. 304-308.

Cacho, Marta, "Una embajada concepcionista a Roma y un lienzo conmemorativo de Luis Cousin (1633)", en Colomer, José Luis (coordinador), Arte y diplomacia de la Monarquía Hispánica en el siglo XVII, Madrid, Fernando Villaverde, 2003, pp. 415-426

Calonaci, Stefano, “““Accordar lo spirito col mondo”. Il cardinal Ferdinando de Medici a Roma negli anni di Pio V e Gregorio XIII”, Rivista Storica Italiana, 112, 2000, pp. 5-74

Campagna Cicala, Francesca, "Intorno all'attività di Caravaggio in Sicilia. Due momenti del caravaggismo siciliano: Mario Minniti e Alonzo Rodríguez", en Caravaggio in Sicilia, il suo tempo, il suo influsso, cat. exp. (Siracusa), Palermo, Sellerio, 1984, pp. 101-144.

De Carlos Morales, Carlos Javier, y Martínez Millán, José (coordinadores), Felipe II (1527-1598). La configuración de la Monarquía Hispana, Salamanca, Junta de Castilla y León, 1998.

Cecchi, Alessandro, en Hochmann, Michel (comisario), Villa Medici. Il sogno di un cardinale. Collezioni e artisti di Ferdinando de' Medici, cat. exp., Roma, De Luca, 1999, pp. 136-137, núm. 1; pp. 290-291, núm. 80; pp. 292-293, núm. 81.

Cecchi, Alessandro, y Gasparri, Carlo, La Villa Médicis. 4. Le collezioni del cardinale Ferdinando. I dipinti e le sculture, Roma, École Française de Rome, 2009, p. 86, núm. 87(187).

Celio, Gaspare, Memoria delli nomi dell'artefici delle pitture che sono in alcune chiese, facciate, e palazzi di Roma (manuscrito de 1620), Nápoles, Scipione Bonino, 1638, edición en facsímil de Zocca, Emma, Milán, Electa, 1967.

Christiansen, Keith, en Christiansen, Keith, y Mann, Judith W. (comisarios), Orazio e Artemisia Gentileschi, cat. exh. (Roma, Nueva York y Saint Louis), Milán, Skira, 2001, pp. 58-61, núm. 5.

Contini, Roberto, en Strinati, Claudio, y Lindemann, Bernd Wolfgang (comisarios), Sebastiano del Piombo 1485-1547, cat. exp. (Roma y Berlín), Milán, Federico Motta, 2008, pp. 238-239, núm. 60, y pp. 244245, núm. 63.

Dandelet, Thomas, "The Ties that Bind: The Colonna and Spain in the $17^{\text {th }}$ Century", en Hernando Sánchez, Carlos José (coordinador), Roma y España. Un crisol de la cultura europea en la edad moderna, Madrid, SEACEX, 2007, pp. 543-549.

De Dominici, Bernardo, Vite de' pittori, scultori, ed architetti napoletani. Non mai date alla luce da Autore alcuno, Vol. II, Nápoles, Francesco e Cristoforo Ricciardi, 1743

Dern, Alexandra, Scipione Pulzone (ca. 1546-1598), Weimar, Verlag und Datenbank für Geisteswissenschaften, 2003.

Dorati da Empoli, Maria Cristina, Una guida artistica di Roma in un manoscritto secentesco anonimo, edición M.C. Dorati da Empoli, Roma, Gangemi, 2000.

Escudero, José Antonio, Los secretarios de Estado y del despacho (1474-1724), Madrid, Instituto de Estudios Administrativos, 1969.

Falomir, Miguel, "Sebastiano e il 'gusto spagnolo"”, en Strinati, Claudio, y Lindemann, Bernd Wolfgang (comisarios), Sebastiano del Piombo 1485-1547, cat. exp. (Roma y Berlín), Milán, Federico Motta, 2008, pp. 67-71, y pp. 368-369, núm. 121.

Arch. esp. arte, LXXXv, 340, octUBRE-DICIEMBRE 2012, 303-328, ISSN: 0004-0428 
Fasano Guarini, Emma, Ferdinando I de’ Medici, en Dizionario Biografico degli Italiani, Vol. 46, Roma, Istituto della Enciclopedia Italiana, 1996, pp. 258-278.

Golberg, Edward L., "Artistic relations between the Medici and the Spanish courts, 1587-1621", The Burlington Magazine, 138, 1996, Part I, pp. 105-114, y Part II, pp. 529-540.

Goldberg, Edward, "State Gifts from the Medici to the Court of Philip III. The Relazione segreta of Orazio della Rena", en Colomer, José Luis (coordinador), Arte y diplomacia de la Monarquía Hispánica en el siglo XVII, Madrid, Fernando Villaverde, 2003, pp. 115-133.

González Polvillo, Antonio, "La Congregación de Granada, el Inmaculismo sevillano y los retratos realizados por Francisco Pacheco de tres de su principales protagonistas: Miguel Cid, Bernardo de Toro y Mateo Vázquez de Leca", Atrio. Revista de Historia del Arte, 15/15, 2009/10, pp. 47-72.

Gonzalo Sánchez-Molero, José Luis, "Mateo Vázquez de Leca, un secretario entre libros: 1. El escritorio", Hispania. Revista Española de Historia, 65, 2005, pp. 813-846.

Grasso, Monica, "Laureti, Tommaso", en Dizionario Biografico degli Italiani, Vol. 64, Roma, Istituto della Enciclopedia Italiana, 2005, pp. 84-88.

Gutiérrez Pastor, Ismael, "Roma 1618. La Inmaculada Concepción de fray Plácido de Tosantos”, en Condor Oruña, María, Mena Marqués, Manuela, Navarrete Prieto, Benito, y Rocha, Francisco Javier (coordinadores), In sapientia libertas. Escritos en homenaje al profesor Alfonso E. Pérez Sánchez, Madrid, Museo Nacional del Prado y Fundación Focus-Albengoa, 2007, pp. 268-276.

Hazañas y la Rúa, Joaquín, Vázquez de Leca 1573-1649, Sevilla, Sobrinos de Izquierdo, 1918.

Henry, Tom, y Joannides, Paul (comisarios), El último Rafael, cat. exp., Madrid, Museo Nacional del Prado, 2012.

Herrmann Fiore, Kristina, "Sebastiano del Piombo e il 'Cristo portacroce' della Galleria Borghese. Novità dal recente restauro e rapporti con Vittoria Colonna”, Storia dell'arte, 110, 2005, pp. 33-74.

Hibbard, Howard, "Ut picturae sermones: The First Painted Decorations of the Gesù", en Wittkower, Rudolph, y Jaffe, Irma (coordinadores), Baroque Art: The Jesuit Contribution, Nueva York, Fordham University Press, 1972, pp. 29-49.

Kubersky-Piredda, Suzanne, “'Non desidero altro che servirla’. Doni medicei per la corte spagnola di Filippo II”, en Von Bernstorff, Marieke, Ebert-Schifferer, Sybille, y Kubersky-Piredda, Suzanne (coordinadoras), L'arte del dono. Scambio culturale tra Italia e Spagna 1550-1650, Milán, Silvana, en prensa.

Leone de Castris, Pierluigi, Polidoro da Caravaggio. L'opera completa, Nápoles, Electa, 2001.

Lovett, Albert W., Philip II and Mateo Vázquez de Leca: the Government of Spain (1572-1592), Ginebra, Librairie Droz, 1977.

Lucco, Mauro, en Strinati, Claudio, y Lindemann, Bernd Wolfgang (comisarios), Sebastiano del Piombo 1485-1547, cat. exp. (Roma y Berlín), Milán, Federico Motta, 2008, pp. 150-151, núm. 24.

Luti, Filippo, Don Antonio de’ Medici e i suoi tempi, Florencia, Leo S. Olschki, 2006.

Luti, Filippo, "Medici, Antonio de"”, en Dizionario Biografico degli Italiani, Vol. 73, Roma, Istituto della Enciclopedia Italiana, 2009, pp. 22-24.

Macioce, Stefania, Michelangelo Merisi da Caravaggio. Documenti, fonti e inventari 1513-1875, Roma, Bozzi, 2010.

Marías, Fernando, El largo siglo XVI. Los usos artísticos del Renacimiento español, Madrid, Taurus, 1989.

Marini, Maurizio, Caravaggio "Pictor praestantisimus”, Roma, Newton Compton, 2005.

Martinelli, Fioravante, Roma ornata dall'architettura, pittura e scultura (manuscrito de 1660-1663), edición de D’Onofrio, Cesare, Florencia, Vallecchi, 1968.

Martínez Millán, José, "Las controversias sobre la Inmaculada Concepción. Surgimiento de la polémica (1613)", en Martínez Millán, José, y Visceglia, Maria Antonietta (coordinadores), La Monarquía de Felipe III. La Casa del Rey, Madrid, Fundación MAPFRE, 2008, Vol. I, pp. 220-226.

Mateo Gómez, Isabel, "Flandes, Portugal y Toledo en la obra de Luis de Morales: las Vírgenes gitanas o del sombrero", Archivo Español de Arte, 80, 2007, pp. 7-24.

Mazzola, Maria Giuseppina, “Tommaso Laureti e la sua formazione: un'ipotesi per iniziare”, en Aurigemma, Maria Giulia (coordinadora), Dal Razionalismo al Rinascimento. Per i quaranta anni di studi di Silvia Danesi Squarzina, Roma, Campisano, 2011, pp. 107-110.

Mena Marqués, Manuela, en Mena Marqués, Manuela (comisaria), Sebastiano del Piombo y España, cat. exp., Madrid, Museo Nacional del Prado, 1995, pp. 95-104, núm. 5. 
Moretti, Massimo, La “Concezione” di Maria in Spagna: profili storici e iconografici, en Morello, Giovanni, Francia, Vincenzo, y Fusto, Roberto (comisarios), Una donna vestita di sole. L'Immacolata Concezione nelle opere dei grandi maestri, cat. exp. (Ciudad del Vaticano), Milán, Federico Motta, 2005, pp. 79-89.

Moroni, Gaetano, Dizionario di erudizione storico-ecclesiastica, Vol. 59, Venecia, Tipografia Emiliana, 1852.

Mulcahy, Rosemarie, "El arte religioso y su función en la corte de Felipe II", en Checa Cremades, Fernando (comisario), Felipe II. Un monarca y su época. Un príncipe del Renacimiento, cat. exp., Madrid, Sociedad Estatal para la Conmemoración de los Centenarios de Felipe II y Carlos V, 1998, pp. 159-183.

Nicolai, Fausto, "La committenza artistica di Marcantonio II Colonna. Le decorazioni pittoriche dei palazzi 'della Torre' ai Santi Apostoli, di Pio IV sulla via Flaminia e gli esordi romani di Scipione Pulzone", Studi Romani, 54, 2006, pp. 278-319.

Nicolai, Fausto, “An unknown fresco by Tommaso Laureti in the monastery of Tor de' Specchi, Rome”, The Burlington Magazine, 153, 2011, pp. 394-397.

Pacheco, Francisco, Arte de la pintura. Edición del manuscrito original, acabado el 24 de enero de 1638, edición de Bassegoda i Hugas, Bonaventura, Madrid, Cátedra, 1990.

Papi, Gianni, "Andrea Commodi, la vicenda artistica e biografica”, en Papi, Gianni, y Petrioli Tofani, Annamaria (comisarios), Andrea Commodi dall'attrazione per Michelangelo all'ansia del nuovo, cat. exp. (Florencia), Florencia, Polistampa, 2012, pp. 21-47.

Parlato, Enrico, "Enrico Caetani a S. Pudenziana: antichità cristiane, magnificenza decorativa e prestigio del casato nella Roma di fine Cinquecento", en Tosini, Patrizia (coordinadora), Arte e committenza nel Lazio dell'età di Cesare Baronio, Roma, Gangemi, 2009, pp. 143-164.

Pasti, Stefania, "L'influenza di Sebastiano sulla produzione figurativa postconciliare", en Strinati, Claudio, y Lindemann, Bernd Wolfgang (comisarios), Sebastiano del Piombo 1485-1547, cat. exp. (Roma y Berlín), Milán, Federico Motta, 2008, pp. 59-65.

Pérez Sánchez, Alfonso Emilio, "Un curioso documento sobre Morales”, Archivo Español de Arte, 50, 1977, pp. 313-316.

Pérez de Tudela, Almudena, "Un retrato del Cardenal Granvela en la Colección del Patrimonio Nacional", Reales Sitios, 160, 2004, pp. 34-45.

Petrucci, Franca, "Colonna, Ascanio", en Dizionario Biografico degli Italiani, Vol. 27, Roma, Istituto della Enciclopedia Italiana, 1982, pp. 275-278.

Pillsbury, Edmund, "The Cabinet Paintings of Jacopo Zucchi: Their Meaning and Function”, Monuments et Mémoirs, 63, 1980, pp. 187-226.

Poole, Stafford, "The Politics of limpieza de sangre: Juan de Ovando and His Circle in the Reign of Philip II", The Americas. A Quarterly Review of Inter-American Cultural History, 55, 1999, pp. 359-389.

Pupillo, Marco, en Morello, Giovanni, Francia, Vincenzo, y Fusco, Roberto (comisarios), Una donna vestita di sole. L'Immacolata Concezione nelle opere dei grandi maestri, cat. exp., (Ciudad del Vaticano), Milán, Federico Motta, 2005, p. 294, núm. 112.

Redín Michaus, Gonzalo, "Due testamenti e altri documenti di Scipione Pulzone”, Ricerche di Storia dell'arte, 78, 2002, pp. 77-86.

Ricci, Fulvio, en Cesarini, Giovanni, I Cappuccini nella Tuscia. Frati pittori ed opere d'arte per le chiese cappuccine 1535-1779, cat. exp., Viterbo, Associazione Santa Giacinta Marescotti, 2010, pp. 70-73.

Ringbom, Sixten, Icon to Narrative. The rise of the dramatic close-up in fifteenth-century devotional painting, Åbo, Åbo Academy, 1965.

Rivero Rodríguez, Manuel, "El servicio a dos cortes: Marco Antonio Colonna, almirante pontificio y vasallo de la monarquía”, en Martínez Millán, José (coordinador), La corte de Felipe II, Madrid, Alianza, 1994, pp. 305-378.

Roisecco, Niccola, Roma antica, e moderna o sia nuova descrizione Di tutti gl'Edifizj antichi, e Moderni Sagri, e profani della Città di Roma, Roma, Niccola Roisecco, 1765.

Ruiz Manero, José María, “Obras y noticias de Girolamo Muziano, Marcello Venusti y Scipione Pulzone en España”, Archivo Español de Arte, 68, 1995, pp. 365-380.

Ruiz Manero, José María, Pintura italiana del siglo XVI en España. II. Rafael y su escuela, Madrid, Fundación Universitaria Española, 1996.

Arch. esp. arte, LXXXV, 340, OCTUBRE-DICIEMBRE 2012, 303-328, ISSN: 0004-0428 
Salort, Salvador, y Kubersky-Piredda, Susanne, “Art collecting in Philip II's Spain: the role of Gonzalo de Liaño, king's dwarf and Gentleman of the Bedchamber: part I", The Burlington Magazine, 148, 2006, pp. 660-665.

Salort, Salvador, y Kubersky-Piredda, Susanne, “Art collecting in Philip II's Spain: the role of Gonzalo de Liaño, king's dwarf and Gentleman of the Bedchamber: part II", The Burlington Magazine, 149, 2007, pp. 224-231.

Spagnolo, Donatella, “Dal 'Seppellimento di santa Lucia' alle 'Storie della Passione': note sul soggiorno del Caravaggio a Siracusa e a Messina”, en Spinosa, Nicola (comisario), Caravaggio. L'ultimo tempo 16061610, cat. exp., Nápoles, Electa, 2004, pp. 84-85.

Stoenescu, Livia, “Ancient Prototypes Reinstantiated: Zuccari's Encounter of Christ and Veronica of 1594”, The Art Bulletin, 93, 2011, pp. 423-448.

Stratton, Suzanne L., The Immaculate Conception in Spanish Art, Cambridge, Cambridge University Press, 1994.

Strinati, Claudio, “1570-1575. La situazione della pittura a Roma”, en Álvarez Lopera, José (comisario), El Greco. Identità e trasformazione. Creta. Italia. Spagna, cat. exp. (Madrid, Roma y Atenas), Milán, Skira, 1999, pp. 115-129.

Tosini, Patrizia, Girolamo Muziano 1532-1592 dalla Maniera alla Natura, Roma, Bozzi, 2008.

Vasari, Giorgio, Le vite de 'più eccellenti pittori scultori ed architettori (Florencia, Giunti, 1568), edición de Gaetano Milanesi, Florencia, Sansoni, 1906.

Vita Christi edita a sancto Bonaventura, edición de Jean Petit, París, h. 1497.

Zuccari, Alessandro, Arte e committenza nella Roma di Caravaggio, Turín, ERI, 1984.

Fecha de recepción: 12-II-2012

Fecha de aceptación: 26-III-2012 